Document downloaded from:

http://hdl.handle.net/10251/151654

This paper must be cited as:

Benajes, J.; Novella Rosa, R.; De Lima, D.; Thein, KJL. (2017). Impact of injection settings operating with the gasoline Partially Premixed Combustion concept in a 2-stroke HSDI compression ignition engine. Applied Energy. 193:515-530.

https://doi.org/10.1016/j.apenergy.2017.02.044

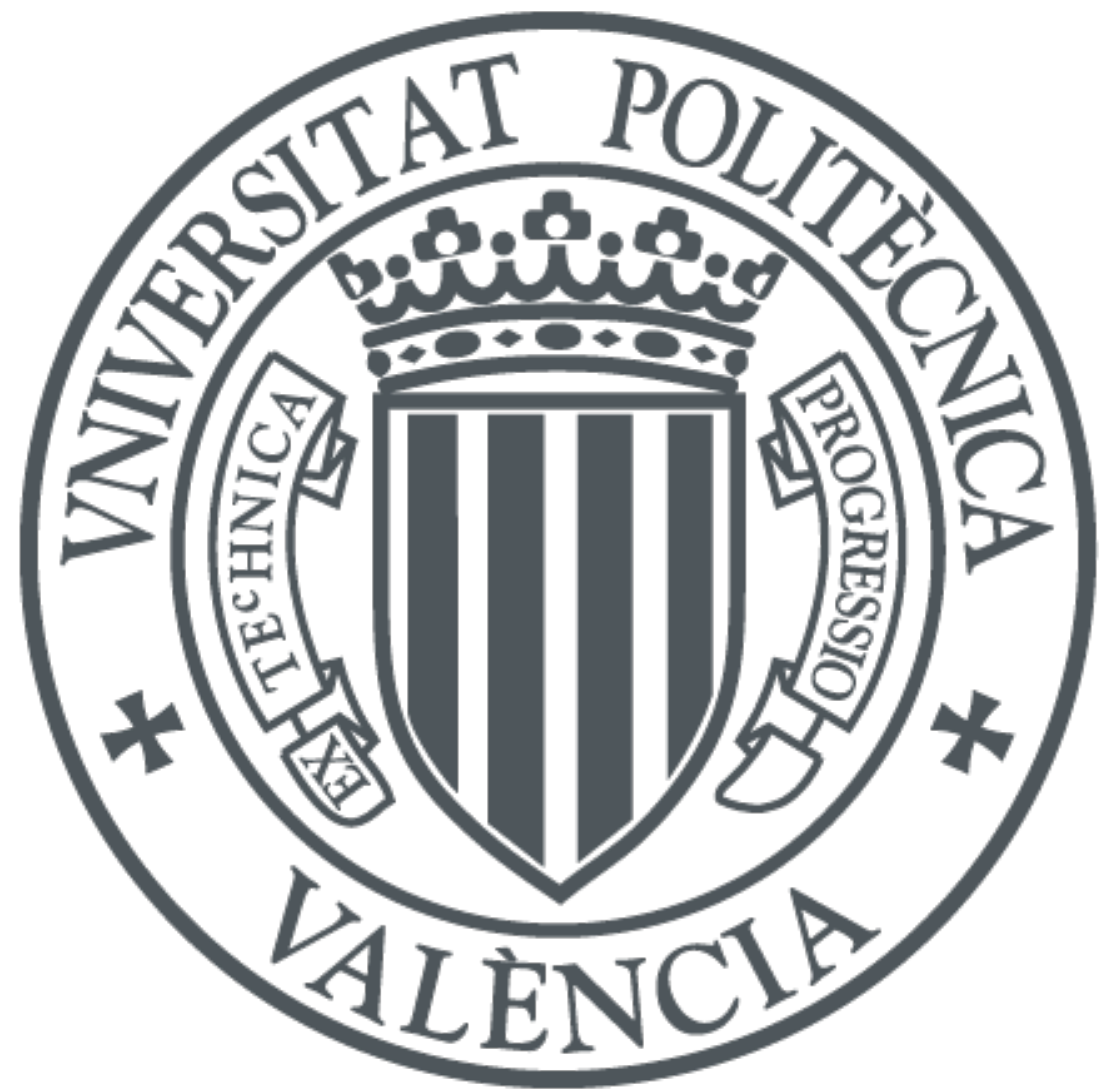

The final publication is available at

https://doi.org/10.1016/j.apenergy.2017.02.044

Copyright Elsevier

Additional Information 


\title{
Impact of injection settings operating with the gasoline Partially Premixed Combustion concept in a 2-stroke HSDI compression ignition engine
}

\author{
J. Benajes, R. Novella*, D. De Lima, K. Thein \\ CMT-Motores Térmicos \\ Universitat Politècnica de València \\ Camino de Vera s/n, 46022, Valencia (Spain) \\ Tel. +34963877650 / Fax +34963877659
}

\begin{abstract}
Partially Premixed Combustion (PPC) using gasoline-like fuels has proven its potential to control or even break the $\mathrm{NO}_{\mathrm{x}}$ and soot emissions trade-off, retaining the high efficiency levels characteristic of the conventional diesel combustion (CDC) concept. However, selecting an appropriate fuel and a suitable injection strategy is essential to assure a successful PPC operation in the full engine map. Additionally, extending the limit of PPC beyond 10 bar IMEP was not possible due to excessively high pressure gradients and onset of knocking-like combustion, so the CDC concept has to be adopted and the conventional trade-off between $\mathrm{NO}_{\mathrm{x}}$ and soot emissions was recovered. Present investigation focuses on evaluating the use of a multiple injection strategy for extending the load range of the PPC concept to medium/high load conditions, when using a commercial RON95 gasoline in a 2-stroke engine under development. Experimental results confirm how with a fine tuned triple injection strategy it is possible to reach extremely low $\mathrm{NO}_{\mathrm{x}}$ and soot levels keeping combustion efficiency over $96 \%$, while indicated efficiency is improved compared to a well-optimized point obtained operating with the CDC concept. Finally, the research work is completed by including 3D-CFD modeling activities that are carried out to contribute to the understanding on how the mixture preparation and stratification prior to the start of combustion impacts its development and particularly the experimentally observed pollutant emissions trends. Keywords: 2-Stroke Engine, CFD Modeling, Gasoline PPC concept, Pollutant Emissions,
\end{abstract}




\section{Introduction}

Among the recently investigated alternatives to reduce fuel consumption and $\mathrm{CO}_{2}$ emissions, an attractive option for extremely downsized engines consists of taking advantage of the 2-stroke engine cycle, which increases drastically the engine specific power by doubling the firing events per crankshaft revolution, to reduce the number of cylinders keeping the NVH (noise, vibration, harshness) performance and similar torque response [1, 2]. With this motivation, an innovative 2-stroke High-Speed Direct Injection (HSDI) compression ignition (CI) engine with poppet valves in the cylinder head is being investigated for a heavily downsized passenger car application, where high power-to-mass ratio is mandatory.

Previous research work performed by the authors in conventional diesel combustion (CDC) confirmed how the proposed 2-stroke architecture provides much higher flexibility in terms of air management settings to control the cylinder conditions and affect combustion environment and final emissions level in a wide range compared to 4-stroke engines [3]. Furthermore, Homogeneous Charge Compression Ignition (HCCI) combustion with diesel fuel was implemented in the proposed 2-stroke engine at low load conditions, and its potential for simultaneous reductions of $\mathrm{NO}_{\mathrm{x}}$ and soot emissions was successfully proven [4]. However, the high reactivity of diesel fuel added to the high residual gas fraction (IGR) characteristic of the scavenge loop architecture, made it impossible to attain a properly-phased combustion even when operating at low loads with optimized engine settings and hardware, so this combustion concept was discarded for the 2-stroke architecture under study [5].

Several problems have been reported along the years in HCCI combustion when using high cetane diesel fuel, such as the control of $\mathrm{HC}$ and $\mathrm{CO}$ emissions [6, 7], or the trade-off between the combustion noise and the engine efficiency [8]. The control of the mixture reactivity has also been reported as problematic [9], event though researches performed by

${ }^{*}$ Corresponding author:

Email address: rinoro@mot.upv.es (R. Novella) 
Zhao et al. could provide some solutions by introducing and adapting new control systems to this kind of combustion $[10,11]$. However, most of these issues can be overcome by operating with retarded injection timings compared to those required to achieve pure HCCI due to the benefits provided by the mixture stratification, such as combustion control by the injection event up to some extent and $\mathrm{HC}$ and $\mathrm{CO}$ reduction by partially avoiding fuel overmixing. This relatively new approach, known as Partially Premixed Combustion (PPC), is achieved by advancing the injection process towards the compression stroke to be detached from the combustion event, enabling partial mixing of the mixture to avoid over-rich regions where soot is formed, whereas $\mathrm{NO}_{\mathrm{x}}$ emissions are reduced by lowering combustion temperatures by the introduction of large amounts of EGR [12].

Research work performed by Kalghatgi et al. in both large [13, 14] and small [15] single-cylinder engines demonstrated that gasoline-like fuels, having a higher resistance to auto-ignition, are better suited for extending mixing times before the onset of combustion than diesel-like fuels. As a result, low engine-out soot and $\mathrm{NO}_{\mathrm{x}}$ emissions were obtained in a wider range of engine loads compared to PPC of diesel-like fuels.

Since this early work, many researchers performed additional numerical [16] and experimental investigations, using various engine size and operating with a large variety of fuels. Heavy-duty 4-stroke diesel engines have been wildly investigated, by Johansson et al. using ethanol [17, 18], or low-to-high octane gasoline fuels [19, 20]. Additionally, studies have also been performed on light-duty 4-stroke diesel engines to compare the results obtained with a large range of octane fuels especially at low loads [21, 22], while Sellnau et al. focused their works at medium-to-high loads [23]. Different injection strategies were explored with various levels of EGR, boost pressure, intake temperature and swirl ratios at different engine loads and speeds. In general, reported results confirmed how it is possible to achieve PPC combustion with very high efficiency, very low $\mathrm{NO}_{\mathrm{x}}$ emissions and lower soot levels compared to CDC in a wide range of load operation. However, even when results are highly promising, many practical issues still remain under investigation before reaching a production-viable powertrain system; i.e. injection systems requirements (injector type and optimum injection pressures), piston and combustion chamber design, boost system requirements, among 
others.

Additionally, there is an optimum zone in the engine map where the ignition characteristics of a given fuel are better matched to the engine operating condition, which results in a limited load range for PPC operation depending on the octane number of the fuel as demonstrated by Johansson et al. [15, 24] and Ciatti et al. [25]. Additionally, the combination of EGR and air/fuel ratio is vital for achieving the in-cylinder conditions (composition and temperature) required for PPC operation [17]. This supposes that the PPC concept needs different fuel reactivities and/or advanced valvetrain and boost/EGR systems [26] to assure proper control over the combustion process, and be able to optimize emissions and efficiency in the entire engine map.

Recent investigations demonstrate how using multiple injection strategies (double and triple injections) have shown to improve fuel-air stratification, minimizing maximum heat release rate, combustion noise, and heat transfer losses; thus, resulting in increased thermal efficiency compared to single injection strategies [26, 27]. Nevertheless, the injection characteristics, such as rail pressure, fuel split ratio between injections and timing of each injection must be carefully optimized depending on the operating condition [22].

Focusing on the 2-stroke HSDI CI engine configuration under development, the potential of the 2-stroke architecture for achieving successful PPC operation in medium/low load conditions was demonstrated, with 5 bar and 3 bar of IMEP, when using a single injection strategy with RON95 gasoline. Low $\mathrm{NO}_{\mathrm{x}}$ emissions (below $0.4 \mathrm{~g} / \mathrm{kWh}$ ) and very low soot emissions were obtained at these load conditions, while $98 \%$ of combustion efficiency and good combustion stability (CoV IMEP under 3\%) was retained. However, to achieve safe high load operation (above 10 bar IMEP) a mixing-controlled combustion had to be adopted, and the conventional trade-off between $\mathrm{NO}_{\mathrm{x}}$ and soot emissions was recovered [28, 29].

Thus, present investigation focuses on evaluating the strengths and limitations of using a multiple injection strategy for extending the load range of the PPC concept to medium/high load conditions, using a commercial RON95 gasoline in the 2-stroke poppet valves HSDI CI engine under development. Additionally, the research work aims to contribute to the understanding of the effects of most important injection parameters over the main combustion 
characteristics, final emissions levels and engine efficiency when operating with the gasoline PPC concept. As specific targets, $\mathrm{NO}_{\mathrm{x}}$ emissions and indicated fuel consumption should be competitive compared to the levels attained operating in conventional diesel combustion, while achieving extremely low levels of soot emissions and high combustion efficiencies (over 95\%) to maintain $\mathrm{CO}$ and $\mathrm{HC}$ emissions within acceptable limits. The implementation of the gasoline PPC concept in an innovative highly-flexible 2-stroke engine opens the possibility of investigating operating conditions beyond those evaluated in 4-stroke engines or even in not-so-flexible 2-stroke engines in terms of in-cylinder thermochemical conditions along the combustion process. Thus, the engine was configured to operate with a suitable combination of IGR/EGR ratio and also with tuned Miller cycle in order to use conventional ON95 gasoline fuel efficiently, which is really difficult to reach in 4-stroke engines. In addition, the combination of experimental and CFD modeling activities also provide worth information for the scientific community since it was possible to clarify/confirm the sources of pollutant formation and their relation with local mixture conditions along the combustion process. The analysis of the local evolution of $\mathrm{CO}$ is of especial interest for the authors since it was proven in previous studies how the NOx-soot trade-off observed operating with the conventional diesel combustion is replaced by the Noise-combustion efficiency and NOx-combustion efficiency trade-offs. Then, gaining knowledge about how CO emissions arise and how they evolve along combustion is mandatory to identify potential strategies focused on improving combustion efficiency. Then, this research is a step further in order to identify the real potential of the PPC concept operating with regular gasoline for automotive applications.

\section{Experimental and theoretical tools}

\subsection{Engine architecture and test cell characteristics}

Experimental activities were performed in a single cylinder research version of an innovative two-cylinder 2-stroke HSDI compression ignition engine with scavenge loop, which is currently under development. As a reference, Table 1 contains the main engine specifications. The definition of the engine architecture, boost system requirements, combustion 
chamber geometry and scavenging characteristics, were described in detail in previous publications $[1,2]$. The combustion chamber, shown in Figure 1, has four poppet valves with double-overhead camshafts and a mask in the intake side, designed for baffling the flow of air between the intake and exhaust valves allowing proper scavenging of the burnt gases while keeping short-circuit losses as low as possible during the scavenging period.

[Table 1 about here.]

A hydraulic cam-driven Variable Valve Timing system allows delaying intake and exhaust valve timings with a cam phasing authority of 30 degrees from base timing, as it was detailed in a previous investigation [28]. In this research, the key valve timing angles $(\mathrm{EVO} / \mathrm{EVC} / \mathrm{IVO} / \mathrm{IVC})$ were defined at those CAD where the given valve lift was $0.3 \mathrm{~mm}$.

A conventional piston bowl geometry optimized for diesel combustion was selected for the studies presented in this research, providing a geometric compression ratio of 17.6. Additionally, a common rail HSDI diesel injection system with a 8 hole injection nozzle with $90 \mu \mathrm{m}$ of hole diameter and $148^{\circ}$ included spray angle was selected for testing the PPC concept. Future detailed optimization operating with the PPC concept is expected to provide a better piston/nozzle match in terms of injector number of holes, hole diameter, spray included angle and piston bowl geometry.

For securing proper functioning of the injection system while injecting gasoline, a lubricity additive was added to the calibrated unleaded RON95 gasoline selected for this research. Most important fuel properties are detailed in Table 2.

[Table 2 about here.]

[Figure 1 about here.]

The injector mass flow rate and spray momentum flux were measured in a dedicated test rig; at a suitable range of operating conditions in terms of injection pressure, injector back-pressure and injection duration; following the methodology described in [30, 31] using commercial diesel fuel and also the selected RON95 gasoline. The maximum attainable 
injection pressure when injecting gasoline is limited to 1200 bar, to avoid possible internal leakages inside the injector nozzle and assure proper stability while measuring the injected fuel mass. A gravimetric dynamic fuel meter is used to measured fuel consumption within $0.2 \%$ of accuracy.

The engine laboratory setup used in the experimental test campaign, as well as the required instrumentation and the accuracy of most important measurement equipments are fully described in Fig 2 and Table 3.

[Figure 2 about here.]

[Table 3 about here.]

Among other systems, the engine test cell is equipped with independent water and oil cooling circuits, an external compressor unit for providing compressed air and simulate the required boosted conditions, and an additional low pressure EGR system to provide arbitrary levels of cooled EGR even at very high intake pressures.

Data of $\mathrm{O}_{2}, \mathrm{CO}, \mathrm{CO}_{2}, \mathrm{HC}, \mathrm{NO}_{\mathrm{x}}, \mathrm{N}_{2} \mathrm{O}$ and EGR is measured with a state-of-the-art HORIBA gas analyzer. Smoke emissions, in filter smoke number units (FSN), are measured by an AVL 415 Smokemeter.

Additionally, a tracer gas method (using methane as an external gas) is used to experimentally measure the trapping ratio, which is defined as the mass of delivered charge that has been trapped in the cylinder before combustion divided by the mass of delivered charge supplied to the cylinder (fresh air plus EGR) [32, 33]. The internal gas recirculation (IGR) ratio is then defined as the fraction of residual gases retained from the previous combustion cycle in the total trapped mass in the cylinder. The IGR ratio, total trapped mass at IVC and in-cylinder effective equivalence ratio are estimated using simplified thermodynamic calculations.

Finally, the most relevant global combustion parameters like indicated mean effective pressure (IMEP), peak cylinder pressure $\left(\mathrm{P}_{\max }\right)$, pressure gradient $(\mathrm{dP} / \mathrm{da})$, and combustion stability indicators $\left(\mathrm{CoV}\right.$ IMEP and $\left.\mathrm{CoV} \mathrm{P}_{\max }\right)$ are directly derived from the analysis of the 
cylinder pressure signal; while the start of combustion (SoC), main combustion angles (CA10, CA50, CA90), ignition delay and mixing times are obtained from the calculated rate of heat release (RoHR). A dedicated 0-dimensional combustion analysis software (CALMEC) [34, $35]$ is used to resolve the first law of thermodynamics; taking the cylinder as a control volume independently from the local conditions inside the combustion chamber; and obtain the instantaneous evolution of the energy released by the progress of combustion from measured cylinder pressure signal. The RoHR calculation includes sub-models for considering heat transfer losses, mechanical deformation of the cylinder and blow-by losses. It is worth to note that this 0-dimensional model simplifies the phenomena occurring inside the engine cylinder and cannot provide any information related to spatial thermo-chemical conditions, so it is used mainly to obtain the global combustion parameters; while multi-dimensional numeric calculations are still needed to perform detailed analysis of the cylinder local conditions.

\subsection{Multi-dimensional engine model}

The computational fluid dynamic (CFD) model was built in the CONVERGE CFD platform. Full coupled open and closed cycle computations using the full intake/exhaust and cylinder geometries were carried out since the combustion chamber is non-symmetric. The computational domain at the intake valve closing (IVC) angle is shown in Figure 1. The CFD code uses a structured Cartesian grid with base cell size of $3 \mathrm{~mm}$. Three additional grid refinements linked to flow velocity and temperature were performed by means of an adaptive mesh refinement (AMR) as well as a fixed three level refinement within the spray region.

The injection rate profile was generated from the experimental database available after the injector characterization (mass flow rate and spray momentum flux) performed for the current injection hardware. The diesel-like injection of gasoline is simulated by the standard Droplet Discrete Model. Gasoline fuel physical properties are defined using iso-octane as surrogate fuel. Spray atomization and break-up are simulated by means of the KH-RT model. Turbulent flow is modeled by means of the RNG k- model with wall-functions in order to account for wall heat transfer. Concerning combustion modeling, a direct integration of 
detailed chemistry approach was used by means of the CONVERGE code and the SAGE solver. Finally, the chemical mechanism of a PRF (primary reference fuels) blend of nheptane $(5 \%)$ and iso-octane $(95 \%)$ has been used in as fuel surrogate after calibrating their respective mass fractions to reproduce the ignition characteristic of the RON95 gasoline.

[Figure 3 about here.]

The setup and validation of the CFD model was performed at the baseline case operating with the PPC concept and a three injection strategy. Figure 3 compares the CFD modeled and experimental pressure traces as well as RoHR profiles for the baseline case, including also the data related to exhaust emissions. Although a small difference is observed in the RoHR regarding the onset of combustion, in overall terms, the CFD model is considered as suitable for being used to evaluate the performances of the PPC concept and explain and support general trends experimentally measured in the single cylinder engine. Prior to perform the analysis presented in this paper, the sensitivity of the CFD model has been evaluated by modeling a set of limited operating conditions. Even though some quantitative discrepancies were observed, the trends provided by the CFD model are qualitatively consistent.

\section{Methodology}

The engine operating condition selected for this investigation corresponds to a medium speed (1500 rpm) and medium-to-high load (10.4 bar of IMEP) operating point. The baseline case used to setup and validate the CFD model was measured experimentally in the single cylinder engine. The fueling rate was fixed in the baseline case at $18.8 \mathrm{mg} / \mathrm{stroke}$ to achieve the targeted IMEP equal to 10.4 bar with CA50 at 5 CAD aTDC (Crank-Angle Degree after Top Dead Center). Then, the total injected quantity was kept constant for all subsequent tests along the different studies. Intake air temperature at the surge tank was fixed at $35^{\circ} \mathrm{C}$ while oil and coolant temperatures were maintained at $90^{\circ} \mathrm{C}$. Table 4 contains the most relevant experimental test conditions as well as pollutant emissions and fuel consumption levels previously obtained operating in CDC at this operating point with engine settings optimized to control $\mathrm{NO}_{\mathrm{x}}$ emissions. 
Preliminary values for the most important air management settings were selected using mathematical models of several engine responses, which were previously obtained through dedicated Design of Experiment (DoE) optimization methodology while operating in CDC with the current engine hardware at the selected operating condition. The available statistical models were used as a tool to locate optimum air management settings which provided the desired oxygen concentration at IVC, while ensuring the required temperature profile to attain proper auto-ignition of the cylinder charge around TDC.

A triple injection strategy was selected for all the studies presented in this research. For the reference point (baseline) the three injection pattern included a very small first injection placed at -60 CAD aTDC, a main second injection where most of the fuel is injected at -40 CAD aTDC, and a small third injection close to TDC at -2 CAD aTDC. As it has been previously demonstrated by the authors, the triple injection strategy is expected at medium-to-high load points (here 10.4 bar IMEP) to help in achieving the load target while avoiding/mitigating knock tendency [36]. For this investigation, the injection timing is referred to the Start of Energizing (SoE) current of the injector instead the actual Start of Injection (SoI), which happens a few crankangle degrees (1.5 to 2 CAD) after the SoE due to the hydraulic delay cause by the needle lift.

[Table 4 about here.]

The range for sweeping the injection timing was pre-defined with the aid of the CFD model by performing parametric studies of each of the three injections. Later on, the trends observed in the calculations were experimentally validated by measuring the defined test plan directly in the engine.

In a second step, the effect of injection pressure over the performances of the PPC concept was evaluated by performing additional sweeps of the second injection timing, for two different levels (higher and lower) compared to the baseline case. The most relevant engine settings chosen for each parametric variation are detailed in Table 5.

The boundary conditions for the CFD simulations were set according to the experimental previously detailed. The settings for the base case presented in Figure 3 corresponds to test 
included in the first line of Table 5 , with the $1^{\text {st }}$ injection set at -60 CAD aTDC. The $2^{\text {nd }}$ injection sweep shown in Figure 6 corresponds to the second line of Table 5, with SoE2 varying from -50 to -34 CAD aTDC. Finally, the $3^{\text {rd }}$ injection sweep shown in Figure 12 corresponds to the fifth line of Table 5, with SoE3 varying from -12 to +8 CAD aTDC.

[Table 5 about here.]

\section{Results and discussion}

Table 5 shows the main air management settings selected for PPC operation. They correspond to considerably higher EGR rate (43.5\%), higher intake pressure (2.75 bar), higher $\Delta \mathrm{P}$ (0.71 bar), and higher overlap duration (78.4 CAD) compared to the optimum values found operating in $\mathrm{CDC}$. This combination of air management settings provided $67 \%$ of trapping ratio, $67 \mathrm{~kg} / \mathrm{h}$ of delivered flow and $35 \%$ of IGR ratio, with in-cylinder global equivalence ratio $\left(\Phi_{\text {cyl }}\right)$ equal to 0.83 , temperature and oxygen concentration at IVC ( $\mathrm{T}_{\mathrm{IVC}}$ and $\mathrm{YO}_{2, \mathrm{IVC}}$ ) of $180^{\circ} \mathrm{C}$ and $12 \%$ respectively, and $4 \%$ of oxygen concentration at EVO $\left(\mathrm{YO}_{2, \mathrm{EVO}}\right)$. Experimental results demonstrated the small effect of injection settings on air management characteristics, so most important gas cylinder conditions remained unaltered regardless of the SoE or the injection pressure.

\subsection{Effect of $1^{\text {st }}$ injection timing}

For the baseline case (SoE1 -60, SoE2 -40 and SoE3 -2 CAD aTDC), the CFD model is used to confirm that liquid fuel impingement into the cylinder walls coming from the very early $1^{\text {st }}$ injection, can be avoided by injecting only a small fraction of the total fuel mass, even when using a $148^{\circ}$ spray included angle injector and a relatively high injection pressure of 850 bar. Moreover, results showed how sweeping the timing of $1^{\text {st }}$ injection has negligible effect over the combustion onset and RoHR, as it is experimentally confirmed in Figure 4 for SoE1 between -66 and -54 CAD aTDC. Additionally, SoE1 also has a small impact on exhaust emissions, except for a slight increase in $\mathrm{HC}$ for the cases with earliest SoE1 as it was expected, and as shown in Figure 5. Further analysis will be primarily focused on describing the effects of the timing of the $2^{\text {nd }}$ and $3^{\text {rd }}$ injections. 
The main application of this early injection is then mainly to provide the required amount of fuel to sustain the demanded IMEP, avoiding to inject this fuel in either of the other events where it could interfere with the combustion conditions and pollutants formation. Its only side effect is the $\mathrm{HC}$ generation, the event then has to be optimized consequently the medium-to-high load range.

\subsection{Effect of $2^{\text {nd }}$ injection timing}

The effect of the second injection timing (SoE2) on the characteristics of the combustion process over the RoHR is shown in Figure 6 for CFD model (upper plot) and experimental results (lower plot). For the CFD calculation, SoE2 was swept from -34 to -52 CAD aTDC for the reference sweep with SoE3 in -2 CAD aTDC, while in the case of experimental results the parametric variation stops at SoE2 -42 CAD aTDC due to poor combustion stability and appearance of misfire conditions for earlier SoE2. Both CFD and experimental results reveal how the second injection controls both the onset of combustion and its phasing (represented by the CA50). Early SoE2 shifts both SoC and CA50 towards the expansion stroke, as shown in Figure 6, causing combustion to become smother and misfire trending; while late SoE2 advances both SoC and CA50 toward the TDC, rapidly approaching toward knocking-like conditions. This trend was observed at different operating conditions and it is well-understood as it is explained considering the impact of SoE2 over the local equivalence ratio distribution just before the onset of combustion [37]. The potential of SoE2 to control the combustion profile and manage the combustion noise and applications of this behavior have been also investigated by the authors [38].

It is interesting to improve the understanding about the relation between local in-cylinder conditions along the combustion process and exhaust emissions formation / destruction. Therefore, Figure 7 shows the exhaust emissions experimentally obtained when sweeping SoE2. Comparing with a well-optimized CDC results, PPC proves to reduce significantly 
the $\mathrm{NO}_{\mathrm{x}}$ and soot emission levels, while $\mathrm{CO}$ and $\mathrm{HC}$ emissions increase. In the PPC concept $\mathrm{NO}_{\mathrm{x}}$ formation is controlled keeping the combustion temperature below $2400 \mathrm{~K}$ by using high EGR rates. On the counterpart, soot formation appears in the high temperature and rich equivalence ratio regions; so for the current injection strategy, the $3^{\text {rd }}$ event is the one acting as the main source of soot emissions by increasing local equivalence ratios towards rich conditions by the time where combustion starts.

[Figure 6 about here.]

Then, advancing SoE2 brings a reduction in $\mathrm{NO}_{\mathrm{x}}$ emissions as the straight effect of retarded and softened combustion process with lower combustion temperatures; while soot formation is also decreased due to the extended ignition delay and therefore increased mixing time available for the $3^{\text {rd }}$ injection (separating this late injection from combustion is a key to avoid soot formation). However, $\mathrm{CO}$ and $\mathrm{HC}$ emissions increase when SoE2 is advanced and CA50 is delayed, as observed in Figure 7, so it appears a clear trade-off between the levels of $\mathrm{NO}_{\mathrm{x}}$-soot and $\mathrm{HC}-\mathrm{CO}$ that is worth to be further investigated. In addition, the levels for both emissions are considerably higher compared to the optimized reference values measured while operating in conventional diesel combustion.

[Figure 7 about here.]

[Figure 8 about here.]

[Figure 9 about here.]

[Figure 10 about here.]

Then, to better understand $\mathrm{CO}$ and $\mathrm{NO}_{\mathrm{x}}$ trends, Figure 8 illustrate how the CFD results are used to represent the mass of $\mathrm{CO}$ and NO in iso-lines as function of the crankangle and the equivalence ratio, for the two cases with SoE2 located in -42 CAD aTDC (left) and in -34 CAD aTDC (right) respectively. 
The mass of $\mathrm{NO}$ which later will be transformed to $\mathrm{NO}_{2}$ and will account for the majority of the $\mathrm{NO}_{\mathrm{x}}$ emissions, is formed in the equivalence ratio zone between 0.5 and 1.2 , for both the early and late SoE2 cases. The lower NO mass shown by the constant mass lines colored in blue for the case of SoE2 -42 , is a consequence of lower local temperatures, given by the later onset of combustion and retarded CA50 with softened and longer RoHR as it is confirmed by its spatial distribution included in Figure 9.

In the case of $\mathrm{CO}$, it can be distinguished two main regions where $\mathrm{CO}$ is formed, the first region is located in the rich equivalence ratio zone ( $\Phi$ between 1 and 2 ) where there is also high temperatures so the $\mathrm{CO}$ formed in this conditions will likely be oxidized along the combustion process; while the second region appears at areas with lean equivalence ratio ( $\Phi$ below 1 and 0.4 ) and medium-low temperatures, where the $\mathrm{CO}-\mathrm{CO}_{2}$ conversion will be difficult if combustion temperatures are not high enough. As confirmed by the CO spatial distribution shown in Figure 10, in the case of SoE2 -42 CAD aTDC the CO mass formed in the lean equivalence ratio and low temperature zone near the cylinder walls in the squish region is not properly oxidized. Therefore, the final CO level which results as a balance between formation and destruction processes is consequently increased. Imaging studies and multi-dimensional simulations performed by Musculus et al. also support this spatial mixture formation in the case of light duty engines, operating with conventional wide-angle injector geometry and typical spray targeting, while running in PPCI conditions with an early injection strategy, which is also closely linked to $\mathrm{CO}$ formation and oxidation processes and final CO emission level [39].

Experimental results shown in Figure 7 also evidence a sharp increase in HC emissions, and the expected reduction in combustion efficiency, for SoE2 earlier than -38 CAD aTDC. The CFD model results included in Figure 11 reveal that when the $2^{\text {nd }}$ injection is placed earlier than -36 CAD aTDC (with the current engine hardware) part of the fuel impacting onto the bowl, piston top-land area and the cylinder liner remains in liquid phase, contributing to an increase in the percentage of fuel film on the walls. Part of this fuel can be evaporated later along compression and combustion but for SoE2 earlier than -44 CAD aTDC, the fuel film located close to the cylinder liner cannot be properly evaporated; which 
added to the lower temperatures and slower combustion rates given by the later CA50 will significantly punish the combustion efficiency. It is worth to note, that with the current injection settings and fuel distribution, the fuel impingement coming from the $1^{\text {st }}$ injection can be kept very low; whereas, the $3^{\text {rd }}$ does not contribute to the liquid fuel film in the walls because it is injected near to TDC completely inside the bowl.

[Figure 11 about here.]

In general, combustion efficiency is relatively lower when operating in PPC compared to $\mathrm{CDC}$, and it follows the observed increase in $\mathrm{CO}$ and $\mathrm{HC}$ emissions, even if it remains in levels over $96 \%$ and $97 \%$, which is in the range of similar results reported in the literature $[23,26]$ when using high octane fuels. Finally, indicated efficiency ranges between $46.5 \%$ and $47.5 \%$ corresponding to ISFC ranging between 181 to $178 \mathrm{~g} / \mathrm{kWh}$, so ISFC decreases by $10 \%$ compared to the optimum point in CDC. Despite the clear benefits in indicated efficiency, if the mechanical power demanded by the air loop devices is taken into account to correct

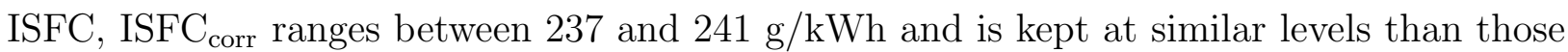
obtained in CDC, due to the increase in mechanical power demanded by the supercharger to achieve the highly demanding equivalence ratio and external EGR rate combinations required to operate in $\mathrm{PPC}$.

The knowledge acquired during these experimental and numerical investigations can be directly implemented when calibrating the engine, as a very fine tuning of the $2^{\text {nd }}$ injection is mandatory to fully map the engine for real condition applications. It controls directly the overmixed lean zones where non-oxidizable $\mathrm{CO}$ is formed, and its impact on the SoC also influences the stratification of the $3^{\text {rd }}$ injection.

\subsection{Effect of $3^{\text {rd }}$ injection timing}

The effect of SoE3 on the RoHR profile is shown in Figure 12 for CFD simulations (top plots) and experimental results (bottom plots). In CFD simulations, the SoE3 was swept from -12 to 8 CAD aTDC, while in the experiments it was swept from -8 to 2 CAD aTDC, being limited by the onset of knocking combustion on earlier SoE3 and the very high 
soot emissions on later SoE3. Both CFD and experimental results evidence small effect of SoE3 on the start of combustion, which is mainly controlled by the $2^{\text {nd }}$ injection. On the contrary, the influence of SoE3 on the development of the combustion process is important as observed in the RoHR profiles. Advancing SoE3 increases the ignition delay and the available mixing time, allowing partial mixing of the fuel injected during this $3^{\text {rd }}$ injection, so the reactivity of the global mixture at the SoC increases and combustion trends to knocking conditions as indicates the fast and short RoHR profile observed in Figure 12. On the contrary, retarding SoE3 shortens the ignition delay and the available mixing time and, as a result, the combustion of the fuel injected in this $3^{\text {rd }}$ injection shifts from a highly premixed process to a mixing-controlled process with the critical impact on emissions explained later.

The experimental results shown in Figure 13 corroborates that $\mathrm{P}_{\max }, \mathrm{dP} / \mathrm{da}_{\max }$ and noise are substantially increased when advancing SoE3; reaching extremely high levels for the earliest SoE3 (150 bar, over 20 bar/CAD and 100 dB, respectively, in this case). However, the effect of retarding SoE3 from -2 CAD aTDC (baseline) to later CAD, on $\mathrm{P}_{\max }$, pressure gradient and noise is moderate despite the longer combustion duration. Finally, $\mathrm{CoV} \mathrm{P}_{\max }$ levels (which is a commonly used parameter for combustion stability diagnosis and misfire rate evaluation) assure suitable combustion stability independently from SoE3 and, as in the case of the SoC, the cycle-to-cycle dispersion is mostly controlled by the $2^{\text {nd }}$ injection.

[Figure 12 about here.]

[Figure 13 about here.]

Local conditions were extracted from the CFD simulations in order to further understand the sensitivity of the combustion process to SoE3. This analysis was performed at CA10 as it is a suitable tracer of the onset of combustion. Then, the local equivalence ratio distribution generated by the three injections will be investigated in detail.

Figure 14 shows a detailed description of the fuel mass at different $\Phi$ (Figure 14 topleft plot) and a summary in form of histogram (Figure 14 top-right plot), together with the spatial distribution of $\Phi$ in a plane cutting the combustion chamber (Figure 14 bottom plot). 
The analysis includes three different SoE3 cases: SoE3 -2 CAD a TDC (baseline), SoE3 -12 CAD aTDC (earliest) and SoE3 8 CAD aTDC (latest).

[Figure 14 about here.]

For the earliest SoE3 the fuel mass within the most reactive equivalence ratios zone is substantially increased compared to the baseline, explaining the higher reactivity of the charge and the faster and sharper RoHR profile trending to knock conditions. In the baseline SoE3, the $3^{\text {rd }}$ injection is being mixed so there is a clear stratification on local equivalence ratios from rich to lean values. For the latest SoE3, the $3^{\text {rd }}$ event has not been injected yet by the time where CA10 occurs, as seen in the RoHR shown in Figure 12, so the $\Phi$ distribution corresponds to the mixing conditions of the $1^{\text {st }}$ and $2^{\text {nd }}$ injections; and finally the $3^{\text {rd }}$ burns in mixing-controlled conditions.

[Figure 15 about here.]

In terms of exhaust emissions, Figure 15 confirms how retarding SoE3 decreases $\mathrm{NO}_{\mathrm{x}}$ due to the slight reduction in local temperatures caused by the smother and longer combustion process. However, soot emissions increase due to reduced mixing times thus extended mixing-controlled stage, recovering the $\mathrm{NO}_{\mathrm{x}}$-soot trade-off characteristic of the CDC concept. This is corroborated by the trend followed by CO emissions since they also slightly increase retarding SoE3 as a result of worse $\mathrm{CO}$ oxidation into $\mathrm{CO}_{2}$ due to the shifting of combustion towards the expansion stroke. HC emissions remained almost constant because they are mostly influenced by the $1^{\text {st }}$ and $2^{\text {nd }}$ injections. Figure 15 shows how combustion efficiency is always higher than $97 \%$ and it is basically independent from SoE3, while indicated efficiency is at levels around $47 \%$ and it is neither substantially affected. Finally, ISFC slightly increases advancing SoE3 due to the fast and short combustion close to knocking conditions, going from $178 \mathrm{~g} / \mathrm{kWh}$ to $181 \mathrm{~g} / \mathrm{kWh}$ and as consequence $\mathrm{ISFC}_{\text {corr }}$ also increase from $236 \mathrm{~g} / \mathrm{kWh}$ to $242 \mathrm{~g} / \mathrm{kWh}$.

The direct application for this late event is the control the $\mathrm{NO}_{\mathrm{x}}$-soot trade-off by adjusting the mixing time, and thus the local richness of the mixture. It also influences the 
development of the combustion by affecting the global mixture reactivity, which can help to manage the pressure gradient and noise.

\subsection{Effect of injection pressure}

After discussing the critical impact of local mixing conditions on the characteristics of the combustion process and also on final pollutant emissions, two different levels of injection pressure, $\mathrm{P}_{\text {rail }}$ equal to 750 and 950 bar, were compared against the baseline $\left(\mathrm{P}_{\text {rail }} 850\right.$ bar $)$ to study the effect of the mixing rate while operating with the gasoline PPC concept. Figure 16 shows the rate of heat release for the parametric variation of SoE2 for $\mathrm{P}_{\text {rail }} 750$ and 950 bar, as well as a comparison of the RoHR and injection rate obtained at SoE2 -40 CAD aTDC for the three $\mathrm{P}_{\text {rail }}$ levels.

[Figure 16 about here.]

According to Figure 16, in the case of the higher $\mathrm{P}_{\text {rail }}$ of 950 bar the earliest SoE2 experimentally measured was -40 CAD aTDC before the appearance of misfire cycles. From the previously generated knowledge it is now clear how this misfire tendency is the result of the faster mixing rates that shift the local equivalence ratio distribution towards leaner conditions together with the higher spray momentum flux that pushes the spray further towards the squish region. Then, increasing the mixing rate through higher injection pressure significantly shortened the window for sweeping SoE2 by narrowing the range between knocking-like combustion and misfire.

On the counterpart, Figure 16 (bottom plot) shows how decreasing mixing rate by lowering $\mathrm{P}_{\text {rail }}$ to 750 bar shifted both SoC and CA50 earlier in the cycle, shortening combustion duration and increasing the peak of the RoHR. This is the direct consequence of the slower mixing of the $2^{\text {nd }}$ injection which increased the percentage of fuel mass located in the reactive equivalence ratio zone (between 0.8 and 1.4) consequently enhancing the trend towards knocking-like conditions. Thus, Figure 17 confirms how $\mathrm{P}_{\max }, \mathrm{dP} / \mathrm{da} \mathrm{a}_{\max }$ and noise levels are increase in the case of $\mathrm{P}_{\text {rail }} 750$ bar compared to the baseline and $\mathrm{P}_{\text {rail }} 950$ bar case. Additionally, the trend followed by $\mathrm{CoV} \mathrm{P}_{\max }$ also confirms the combustion stability improvement 
provided by decreasing $\mathrm{P}_{\text {rail }}$ that allows to advance the $2^{\text {nd }}$ injection up to -44 CAD aTDC without misfire. This result is clearly supported by the sharp $\mathrm{CoV} \mathrm{P}_{\max }$ increment observed at SoE2 -42 CAD aTDC from $\mathrm{P}_{\text {rail }} 750$ bar to 850 bar, in fact, testing this SoE2 at $\mathrm{P}_{\text {rail }} 950$ bar was not possible due to the high rate of misfiring cycles.

[Figure 17 about here.]

[Figure 18 about here.]

Focusing on exhaust emissions, increasing $\mathrm{P}_{\text {rail }}$ to 950 bar allowed decreasing smoke emissions compared to the baseline and low $\mathrm{P}_{\text {rail }}$ case, as it is shown in Figure 18, as the combined effect of faster mixing rate and delayed start of combustion which extended the available mixing time for both the $2^{\text {nd }}$ and $3^{\text {rd }}$ injections. On the counterpart, $\mathrm{HC}$ emissions are slightly higher in the case of $\mathrm{P}_{\text {rail }} 950$ bar probably due to increased spray penetration which worsened the fuel impingement into colder wall regions and squish area. $\mathrm{NO}_{\mathrm{x}}$ emissions are slightly higher with lower injection pressure due to the faster and sharper combustion with earlier CA50, while CO is slightly lower due to better oxidation given by the increase in combustion temperatures. As a result of lower $\mathrm{HC}$ and $\mathrm{CO}$ emissions, combustion efficiency is slightly higher in the case of lower $\mathrm{P}_{\text {rail }}$. Finally, the injection pressure seems to have very small effect over ISFC and consequently over indicated efficiency, which remained approximately constant regardless of $\mathrm{P}_{\text {rail }}$.

The trends observed during this study are very similar to results highlighted during previous author's researches focused on the fuel repartition between the injection events [38]. Indeed, the objective was to control the RoHR profile in order to improve the noise / emissions / efficiency trade-offs. The injection pressure demonstrates an additional control over the combustion profile, through different paths: higher injection pressure influences greatly the effects of the second injection (generating higher levels of $\mathrm{HC}$ ) while only affecting the third events by reducing the soot emissions. On the contrary, the fuel distribution proved to affect the main event in reversed ranges (helps reducing $\mathrm{CO}$ and $\mathrm{HC}$ levels), but also to influence the last injection by reducing both $\mathrm{NO}_{\mathrm{x}}$ and soot emissions. 
The injection pressure effects can be considered as complementary to those of the $2^{\text {nd }}$ injection, as increasing the pressure has similar impacts on combustion and emissions as advancing SoE2. Then, as for the $2^{\text {nd }}$ injection, it needs to be carefully adjusting for a engine mapping application. The sensibility even increases at higher injection pressures, as the operating range between knock and misfire is narrowed.

\section{Conclusions}

In this research, a detailed analysis of the multiple injection PPC concept using gasoline as fuel has been carried out by combining experimental and CFD modeling activities. This section summarizes the most relevant conclusions obtained from this investigation.

According to the results, the gasoline PPC concept drastically reduces by $98 \%$ both $\mathrm{NO}_{\mathrm{x}}$ and soot emissions compared to the levels provided by a well optimized CDC concept, leading to a large reduction of the after-treatment demands. Also, the faster and thus shorter combustion observed while operating with this concept, together with lower heat transfer losses, significantly improved the indicated efficiency by around 10\%. However, these benefits obtained in indicated efficiency can be partially or even totally lost after considering the power demanded by the air loop devices to achieve the suitable EGR $/ \Phi_{\text {cyl }}$ combination required to implement the gasoline PPC concept.

As a counterpart, gasoline PPC operation provides worse results in terms of $\mathrm{HC}$ and CO emissions, which is translated in a decrease in combustion efficiency from $99.3 \%$ to 96.5\%. The $1^{\text {st }}$ injection helps to provide the required amount of fuel without affecting the combustion. The analysis carried out by means of CFD modeling confirms how the $2^{\text {nd }}$ injection event induce a liquid fuel spray/wall impingement for its most advanced timings, resulting in an increased $\mathrm{HC}$ formation. CFD results also prove that $\mathrm{CO}$ generates in both rich and lean local equivalence ratio zones, however, while the $\mathrm{CO}$ generated in rich local equivalence ratio zones is finally oxidized the $\mathrm{CO}$ generated in lean local equivalence ratio zones cannot be oxidized due to the low local temperatures, being the basic source of final CO emissions. The other main drawback of the PPC concept is the high level of noise generated by the fast knocking-like combustion process in these medium-to-high load 
conditions, which can be controlled by fine tuning the $3^{\text {rd }}$ injection. Even though, in the optimum point operating with the gasoline PPC concept, noise level is significantly higher compared to that obtained operating with a well optimized CDC concept.

Additionally, the potential of injection pressure to control the local mixing conditions was investigated in detail. Increasing injection pressure shifts the combustion phasing towards the expansion stroke and softens its development, decreasing the cylinder pressure gradients and noise levels. In addition, the lower local equivalence ratios along the combustion process result in reduced soot emissions. As the main negative aspect, the longer spray penetration brought an increase in $\mathrm{HC}$ emissions.

Finally, it is worth to point out that this test campaign was performed with the optimum engine hardware defined operating with the CDC concept, therefore, a detailed study of the piston and injector nozzle geometry to improve their compatibility with the gasoline PPC concept is expected to allow even further improvements. Moreover, future optimization work using a Design of Experiments (DoE) methodology can be useful not only to understand coupled effects that have influence over the combustion and emissions formation processes, but also to find the best injection pattern that can simultaneously fulfill a given set of targets and restrictions.

\section{Acknowledgments}

This work was partly funded by the Generalitat Valenciana, project PROMETEOII/2014/043. The authors kindly recognize the technical support provided by Mr. Pascal Tribotté from RENAULT SAS in the frame of the DREAM-DELTA-68530-13-3205 Project. 


\section{References}

[1] Tribotte P, Ravet F, Dugue V, Obernesser P, Quechon N, Benajes J, et al. Two strokes diesel engine promising solution to reduce co2 emissions. Procedia - Social and Behavioral Sciences 2012;48:2295-314.

[2] Pohorelsky L, Brynych P, Macek J, Vallaude PY, Ricaud JC, Obernesser P, et al. Air system conception for a downsized two-stroke diesel engine. SAE Technical Paper 2012-01-0831; 2012.

[3] Benajes J, Novella R, De Lima D, Tribotte P, Quechon N, Obernesser P, et al. Analysis of the combustion process, pollutant emissions and efficiency of an innovative 2-stroke hsdi engine designed for automotive applications. Applied Thermal Engineering 2013;58:181-93.

[4] Benajes J, Novella R, De Lima D, Dugue V, Quechon N. The potential of highly premixed combustion for pollutant control in an automotive two-stroke hsdi diesel engine. SAE Technical Paper 2012-01-1104; 2012.

[5] Benajes J, Novella R, De Lima D, Quechon N, Obernesser P. Implementation of the early injection highly premixed combustion concept in a two-stroke hsdi engine. SIA Diesel Powertrain Congress 2012, France, June 5-6 2012.

[6] Walter B, Gatellier B. Development of the high power naditm concept using dual mode diesel combustion to achieve zero nox and particulate emissions. SAE Technical Paper 2002-01-1744; 2002.

[7] Hardy WL, Reitz RD. A study of the effects of high egr, high equivalence ratio, and mixing time on emissions levels in a heavy-duty diesel engine for pcci combustion. SAE Technical Paper 2006-01-0026; 2006.

[8] Torregrosa AJ, Broatch A, Garca A, Mnico LF. Sensitivity of combustion noise and nox and soot emissions to pilot injection in pcci diesel engines. Applied Energy 2013;104(0):149-57.

[9] Machrafi H, Cavadias S, Amouroux J. A parametric study on the emissions from an hcci alternative combustion engine resulting from the auto-ignition of primary reference fuels. Applied Energy 2008;85(8):755-64.

[10] Zhao D, Li J. Feedback control of combustion instabilities using a helmholtz resonator with an oscillating volume. Combustion Science and Technology 2012;184(5):694-716.

[11] Zhang Z, Zhao D, Han N, Wang S, Li J. Control of combustion instability with a tunable helmholtz resonator. Aerospace Science and Technology 2015;41:55-62.

[12] Okude K, Mori K, Shiino S, Moriya T. Premixed compression ignition (pci) combustion for simultaneous reduction of nox and soot in diesel engine. SAE Technical Paper 2004-01-1907; 2004.

[13] Kalghatgi GT, Risberg P, ngstrm H. Advantages of fuels with high resistance to auto-ignition in late-injection, low-temperature, compression ignition combustion. SAE Technical Paper 2006-01-3385; 2006.

[14] Kalghatgi G, Risberg P, ngstrm H. Partially pre-mixed auto-ignition of gasoline to attain low smoke 
and low nox at high load in a compression ignition engine and comparison with a diesel fuel. SAE Technical Paper 2007-01-0006; 2007.

[15] Hildingsson L, Kalghatgi G, Tait N, Johansson B, Harrison A. Fuel octane effects in the partially premixed combustion regime in compression ignition engines. SAE Technical Paper 2009-01-2648; 2009.

[16] Das Adhikary B, Ra Y, Reitz R, Ciatti S. Numerical optimization of a light-duty compression ignition engine fuelled with low-octane gasoline. SAE Technical Paper 2012-01-1336; 2012.

[17] Kaiadi M, Johansson B, Lundgren M, Gaynor JA. Sensitivity analysis study on ethanol partially premixed combustion. SAE International Journal of Engines 2013;6(1).

[18] Manente V, Tunestal P, Johansson B. Effects of ethanol and different type of gasoline fuels on partially premixed combustion from low to high load. SAE Technical Paper 2010-01-0871; 2010.

[19] Manente V, Johansson B, Tunestal P, Cannella W. Effects of different type of gasoline fuels on heavy duty partially premixed combustion. SAE International Journal of Engines 2010;2(2):71-88.

[20] Lewander M, Johansson B, Tunestal P. Investigation and comparison of multi cylinder partially premixed combustion characteristics for diesel and gasoline fuels. SAE Technical Paper 2011-01-1811; 2011.

[21] Borgqvist P, Tunestal P, Johansson B. Gasoline partially premixed combustion in a light duty engine at low load and idle operating conditions. SAE Technical Paper 2012-01-0687; 2012.

[22] Das Adhikary B, Reitz R, Ciatti S. Study of in-cylinder combustion and multi-cylinder light duty compression ignition engine performance using different ron fuels at light load conditions. SAE Technical Paper 2013-01-0900; 2013.

[23] Sellnau MC, Sinnamon J, Hoyer K, Kim J, Cavotta M, Husted H. Part-load operation of gasoline direct-injection compression ignition (gdci) engine. SAE Technical Paper 2013-01-0272; 2013.

[24] Solaka H, Aronsson U, Tuner M, Johansson B. Investigation of partially premixed combustion characteristics in low load range with regards to fuel octane number in a light-duty diesel engine. SAE Technical Paper 2012-01-0684; 2012.

[25] Ciatti S, Johnson M, Das Adhikary B, Reitz R, Knock A. Efficiency and emissions performance of multizone stratified compression ignition using different octane fuels. SAE Technical Paper 2013-010263; 2013.

[26] Sellnau MC, Sinnamon J, Hoyer K, Husted H. Full-time gasoline direct-injection compression ignition (gdci) for high efficiency and low nox and pm. SAE International Journal of Engines 2012;5(2).

[27] Kaiadi M, Johansson B, Lundgren M, Gaynor JA. Experimental investigation on different injection strategies for ethanol partially premixed combustion. SAE Technical Paper 2013-01-0281; 2013.

[28] Benajes J, Molina S, Garca A, Monsalve-Serrano J, Durrett R. Conceptual model description of the 
double injection strategy applied to the gasoline partially premixed compression ignition combustion concept with spark assistance. Applied Energy 2014;129(0):1-9.

[29] Benajes J, Novella R, Martn J, De Lima D. Analysis of the load effect on the partially premixed combustion concept in a 2-stroke hsdi diesel engine fueled with conventional gasoline. SAE Technical Paper 2014-01-1291; 2014.

[30] Payri R, Salvador FJ, Gimeno J, Bracho G. A new methodology for correcting the signal cumulative phenomenon on injection rate measurements. Experimental Techniques 2008;32(1):46-9.

[31] Payri R, Garca J, Salvador F, Gimeno J. Using spray momentum flux measurements to understand the influence of diesel nozzle geometry on spray characteristics. Fuel 2005;84(5):551-61.

[32] Olsen D, Hutcherson G, Wilson B, Mitchell C. Development of the tracer gas method for large bore natural gas engines: Part 1 - method validation. Journal of Engineering for Gas Turbines and Power 2002;124(3):678-85.

[33] Olsen D, Hutcherson G, Wilson B, Mitchell C. Development of the tracer gas method for large bore natural gas engines: Part 2 - measurement of scavenging parameters. Journal of Engineering for Gas Turbines and Power 2002;124(3):686-94.

[34] Lapuerta M, Armas O, Hernndez JJ. Diagnosis of di diesel combustion from in-cylinder pressure signal by estimation of mean thermodynamic properties of the gas. Applied Thermal Engineering 1999;19(5):513-29.

[35] Payri F, Molina S, Martn J, Armas O. Influence of measurement errors and estimated parameters on combustion diagnosis. Applied Thermal Engineering 2006;26(23):226-36.

[36] Benajes J, Novella R, De Lima D, Tribotte P. Investigation on multiple injection strategies for gasoline ppc operation in a newly designed 2-stroke hsdi compression ignition engine. SAE Int J Engines 2015;2015-01-0830.

[37] Benajes J, Novella R, De Lima D, Tribotté P. Analysis of combustion concepts in a newly designed two-stroke high-speed direct injection compression ignition engine. International Journal of Engine Research 2015;16(1):52-67.

[38] Benajes J, Martn J, Novella R, Thein K. Understanding the performance of the multiple injection gasoline partially premixed combustion concept implemented in a 2-stroke high speed direct injection compression ignition engine. Applied Energy 2016;161:465-75.

[39] Musculus MPB, Miles PC, Pickett LM. Conceptual models for partially premixed low-temperature diesel combustion. Progress in Energy and Combustion Science 2013;39(23):246-83. 


\section{List of Figures}

$13 \mathrm{D}$ view of the combustion chamber designed for the two-stroke engine architecture (Patent Renault FR2931880) . . . . . . . . . . . . . . . . 26

2 Layout of the engine test cell . . . . . . . . . . . . . . . . . 27

3 CFD model validation at the reference point operating with gasoline PPC concept. . . . . . . . . . . . . . . . . . 28

4 Effect of SoE1. RoHR and injection pulse for experimental results. . . . . . . 29

5 Effect of SoE1. Exhaust emissions and efficiencies for experimental results. . 30

6 Effect of SoE2. RoHR and injection pulse for CFD (top plot) and for experimental results (bottom plot). . . . . . . . . . . . . . . . 31

$7 \quad$ Effect of SoE2. Exhaust emissions and efficiencies for experimental results. . 32

$8 \mathrm{NO}$ and CO mass distribution as function of local equivalence ratio and crankangle for SoE2 -42 (left plots) and -34 (right plots) CAD aTDC. . . . . 33

9 Spatial NO distribution as function of crankangle for SoE2 -42 (left plots) and -34 (right plots) CAD aTDC . . . . . . . . . . . . . . . 34

10 Spatial CO distribution as function of crankangle for SoE2 -42 (left plots) and -34 (right plots) CAD aTDC. . . . . . . . . . . . . . . . . . 35

11 Fuel film mass as function of crankangle for SoE2 42, 38 and 34 CAD aTDC (top plot) and $\mathrm{HC}$ with iso-octane mass for SoE2 42 and 34 CAD aTDC (bottom plot). . . . . . . . . . . . . . . . . . .

12 Effect of SoE3. RoHR and injection pulse and for CFD (top plot) and experimental results (bottom plot). . . . . . . . . . . . . . . 37

13 Effect of SoE3. Global combustion parameters for experimental results. . . . 38

14 Local conditions evaluated at CA10. Equivalence ratio distribution as function of fuel mass (top-left plot), histogram of fuel mass (top-right plot) and spatial equivalence ratio distribution (bottom plot) for SoE3 equal to -12, -2 (baseline) and +8 CAD aTDC. . . . . . . . . . . . . . . . . . 39

15 Effect of SoE3. Exhaust emissions and efficiencies for experimental results. . 40

16 RoHR and injection pulse for SoE2 sweep at $\mathrm{P}_{\text {rail }} 750$ (top plot) and 950 bar (center plot). Comparison between injection rate and RoHR profiles (bottom plot). . . . . . . . . . . . . . . . . .

17 Effect of injection pressure. Global combustion parameters for experimental results. . . . . . . . . . . . . . . . . . . . . 42

18 Effect of injection pressure. Exhaust emissions and efficiencies for experimental results. . . . . . . . . . . . . . . . . . . . . . . 


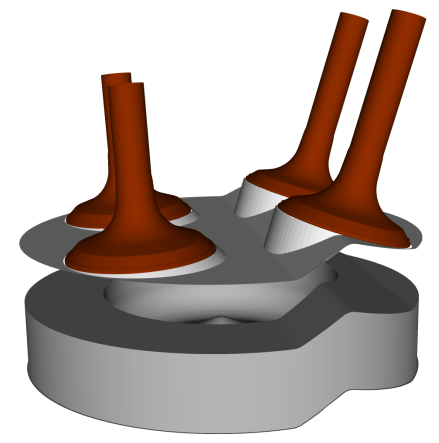

Figure 1: 3D view of the combustion chamber designed for the two-stroke engine architecture (Patent Renault FR2931880) 


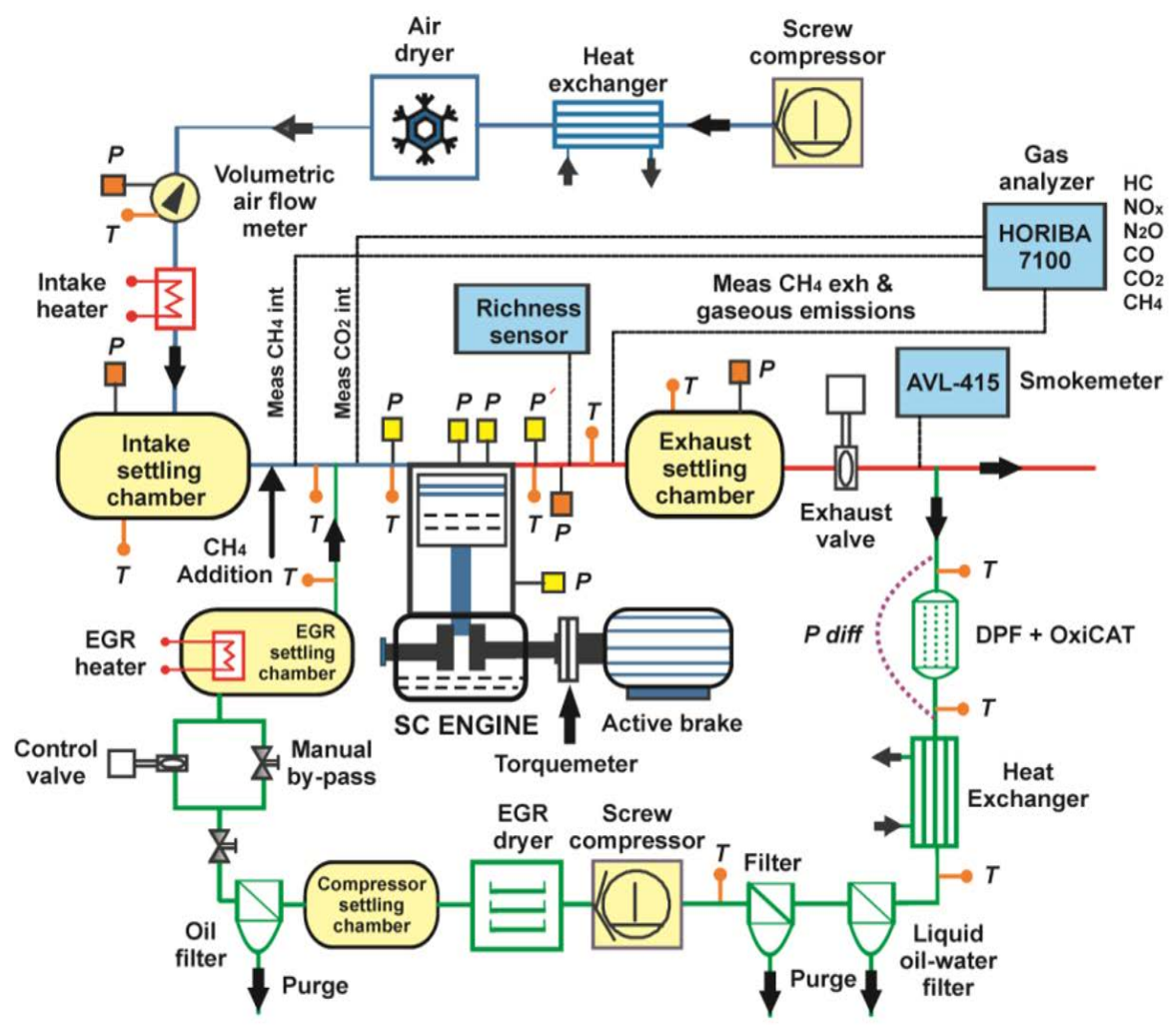

Figure 2: Layout of the engine test cell 

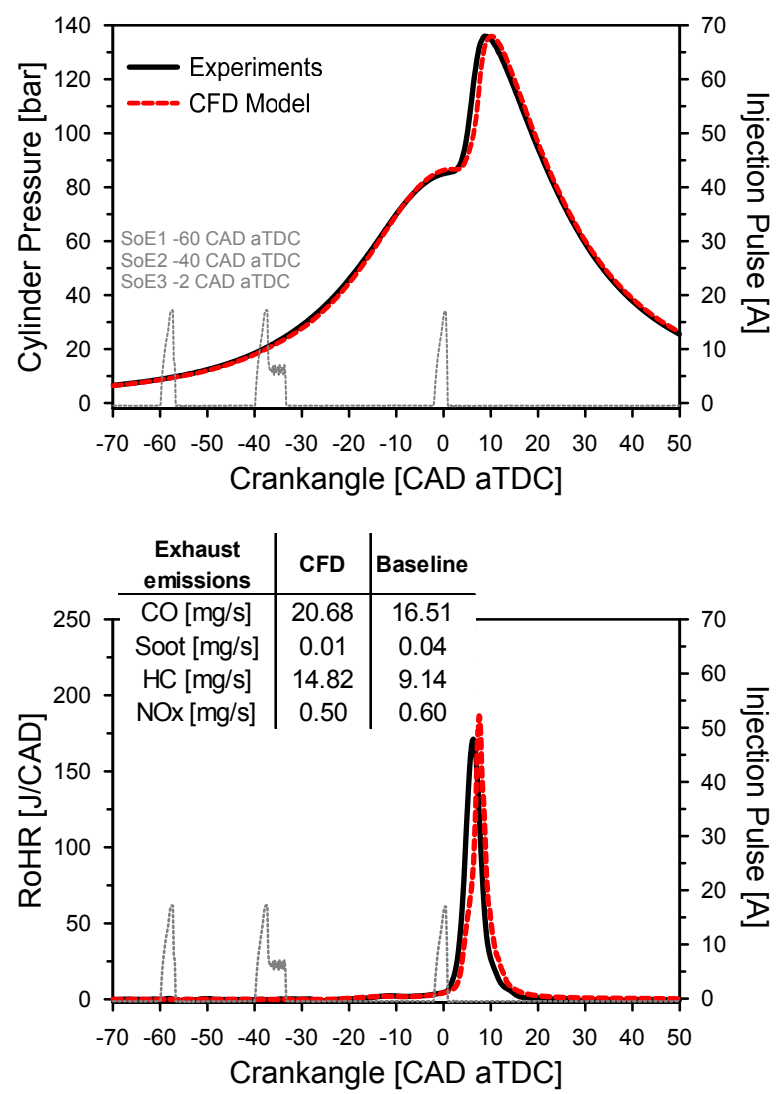

Figure 3: CFD model validation at the reference point operating with gasoline PPC concept. 


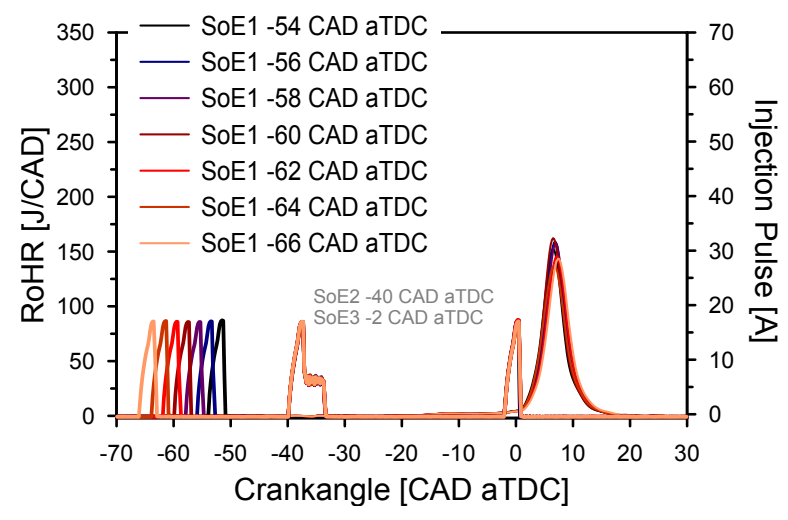

Figure 4: Effect of SoE1. RoHR and injection pulse for experimental results. 

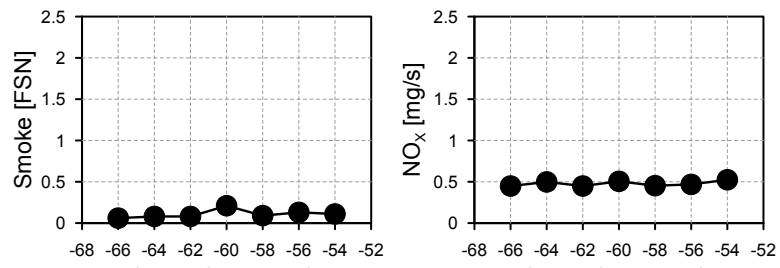

SoE1 [CAD aTDC]

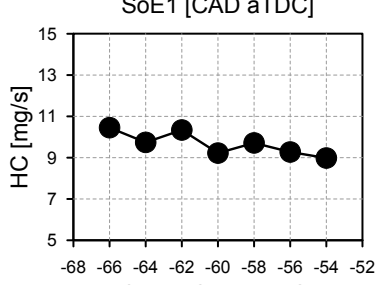

$\begin{array}{lllllllll}-68 & -66 & -64 & -62 & -60 & -58 & -56 & -54 & -52\end{array}$ SoE1 [CAD aTDC] SoE1 [CAD aTDC]
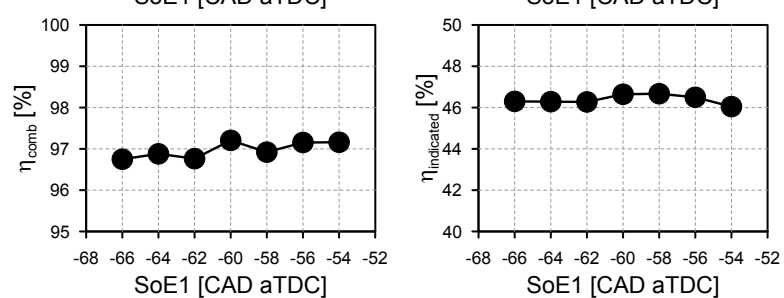

Figure 5: Effect of SoE1. Exhaust emissions and efficiencies for experimental results. 

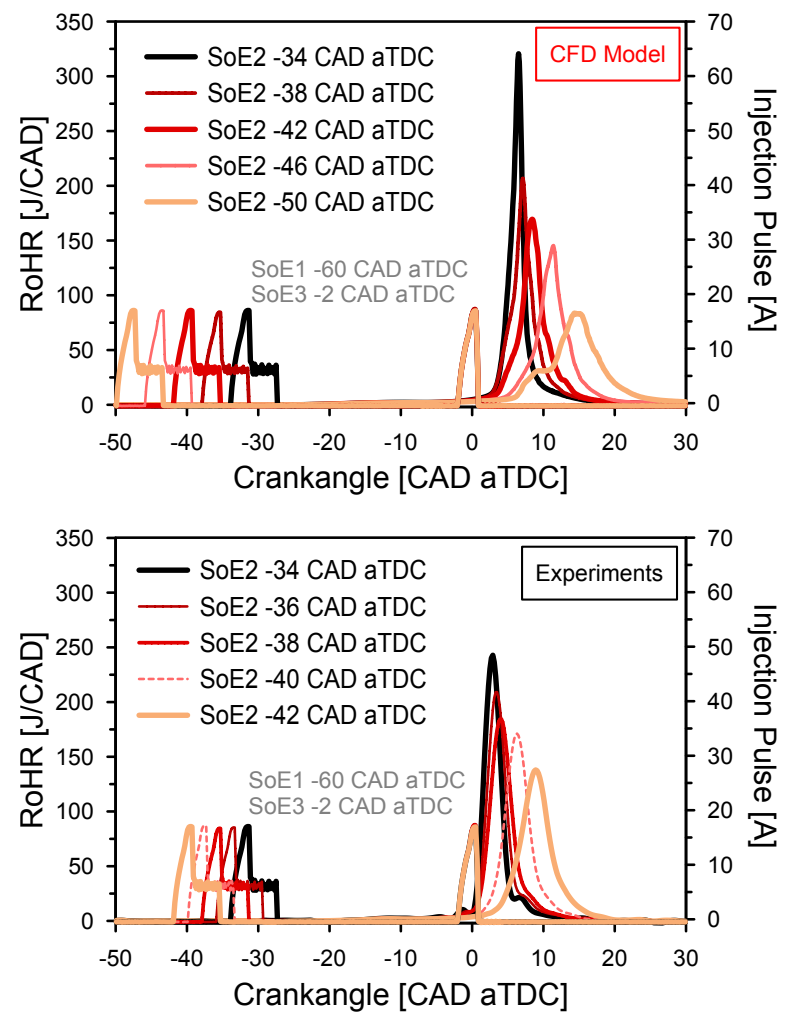

Figure 6: Effect of SoE2. RoHR and injection pulse for CFD (top plot) and for experimental results (bottom plot). 

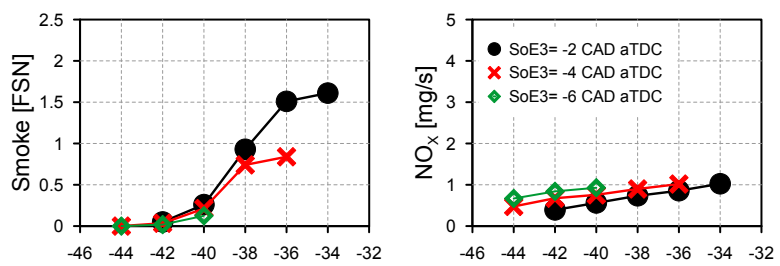

SoE2 [CAD aTDC]
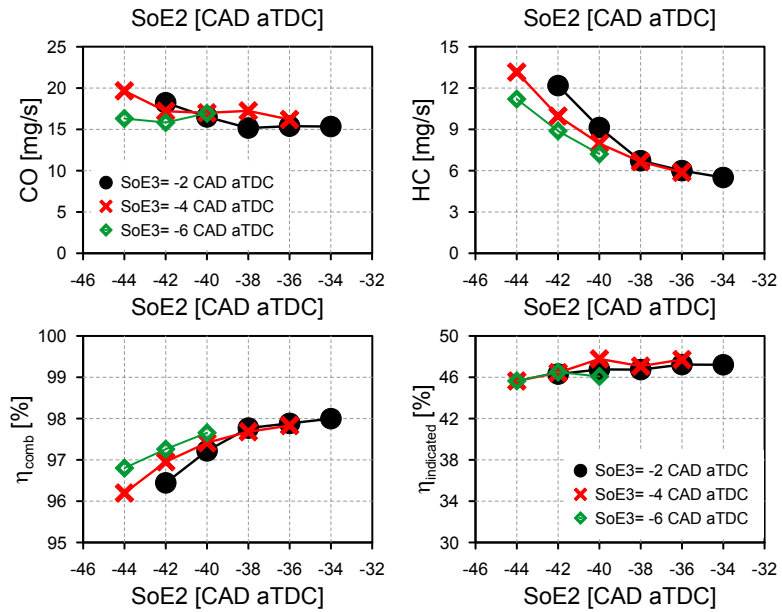

Figure 7: Effect of SoE2. Exhaust emissions and efficiencies for experimental results. 

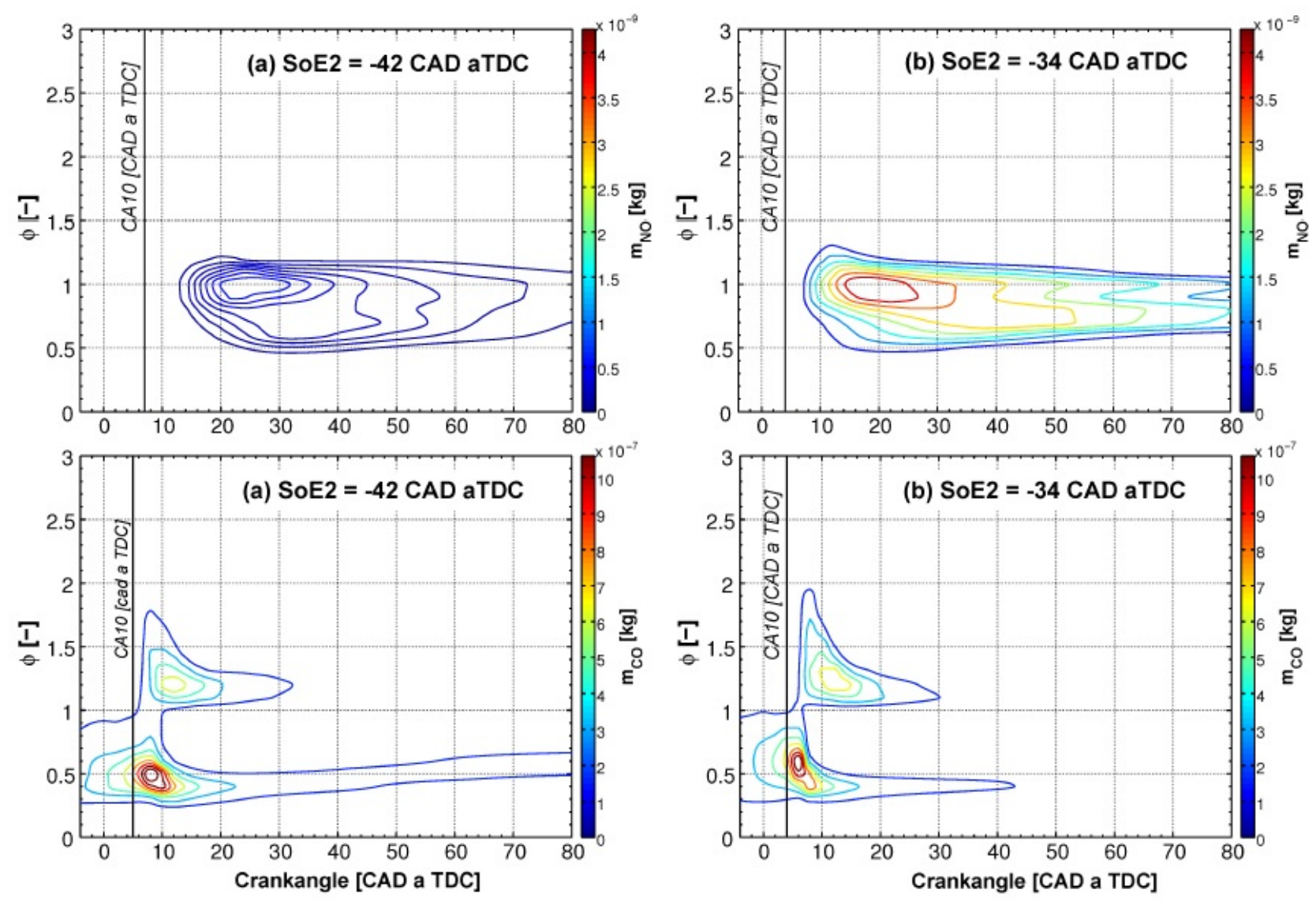

Figure 8: NO and CO mass distribution as function of local equivalence ratio and crankangle for SoE2 -42 (left plots) and -34 (right plots) CAD aTDC. 


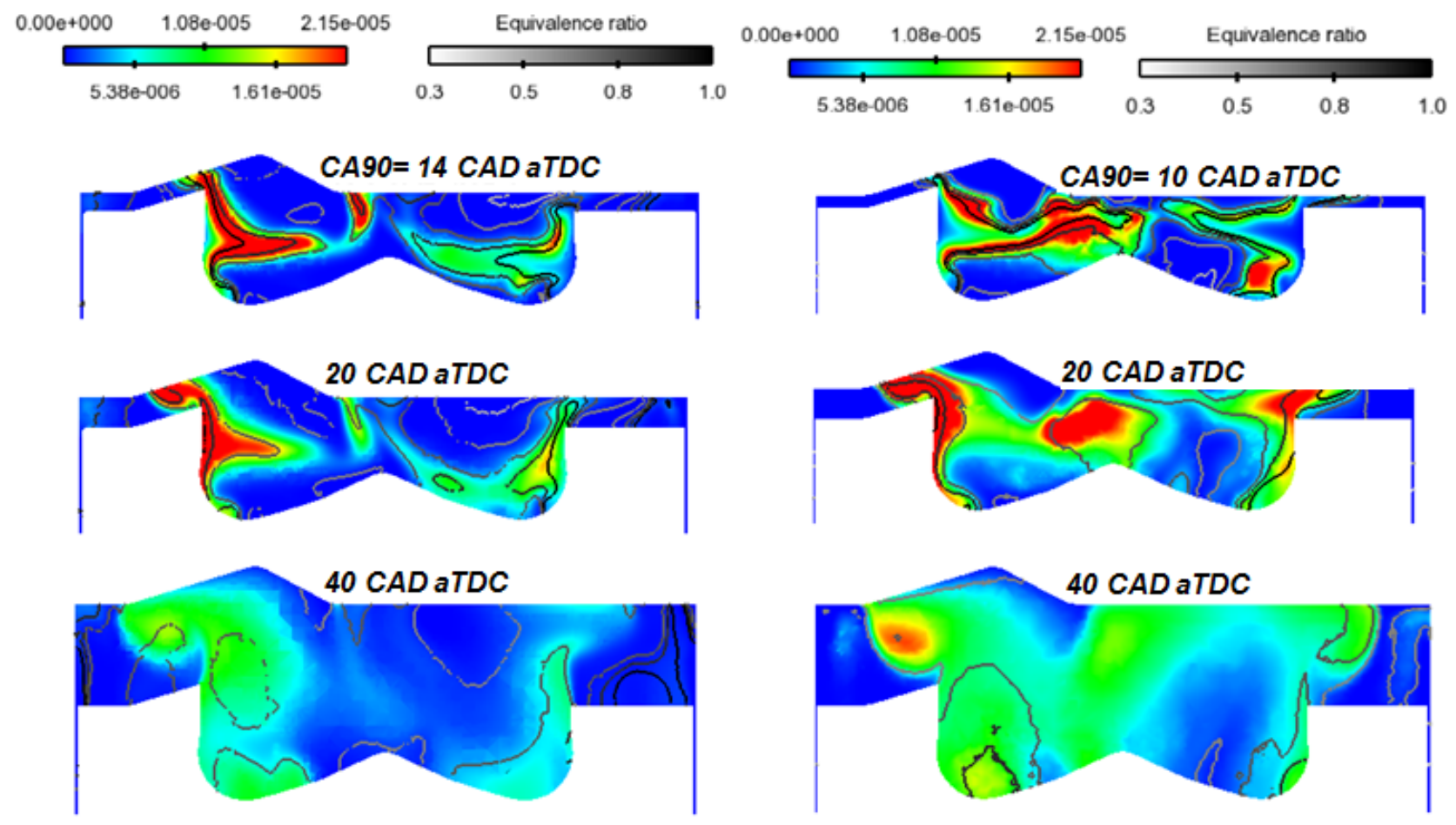

Figure 9: Spatial NO distribution as function of crankangle for SoE2 -42 (left plots) and -34 (right plots) CAD aTDC. 


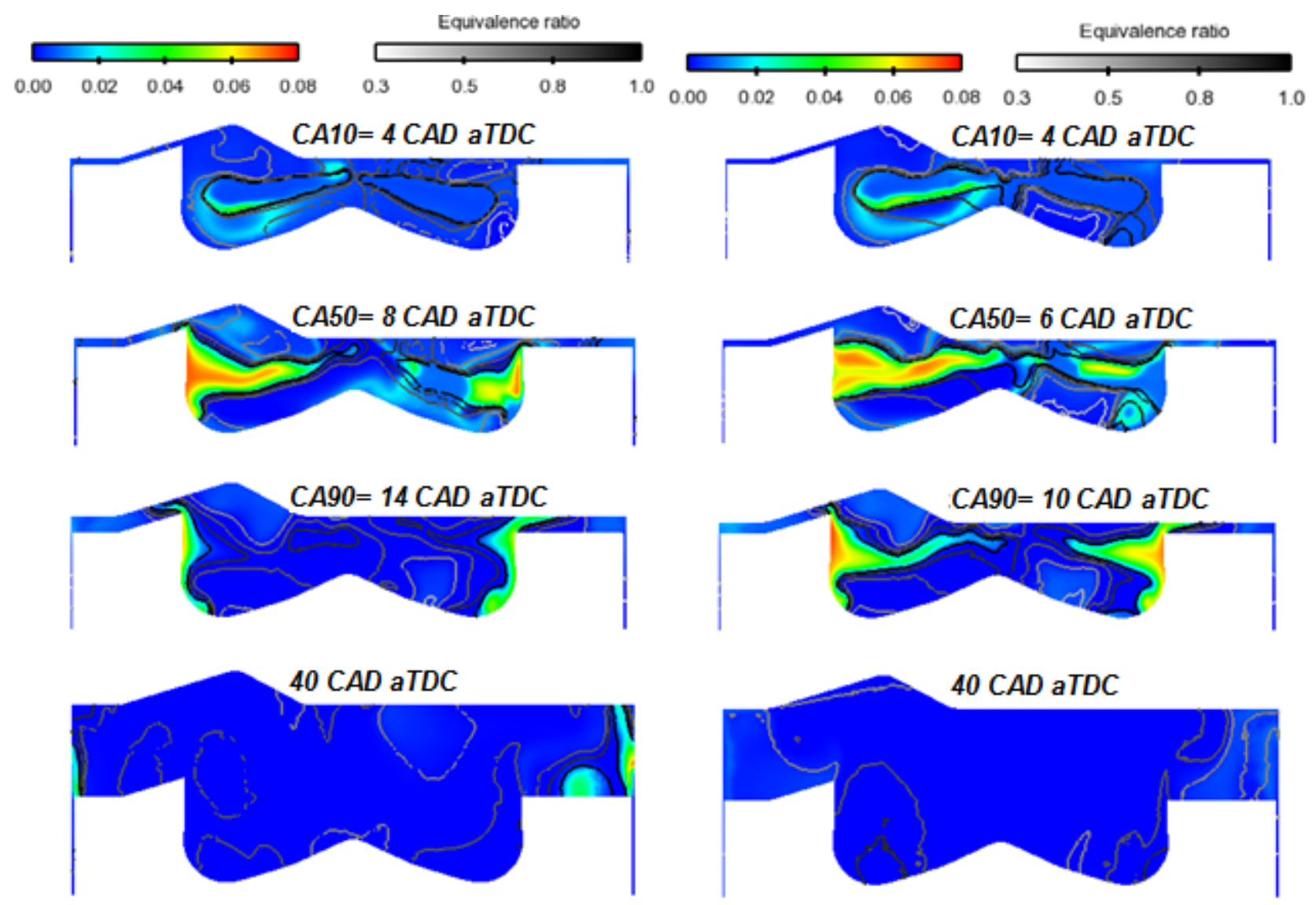

Figure 10: Spatial CO distribution as function of crankangle for SoE2 -42 (left plots) and -34 (right plots) CAD aTDC. 

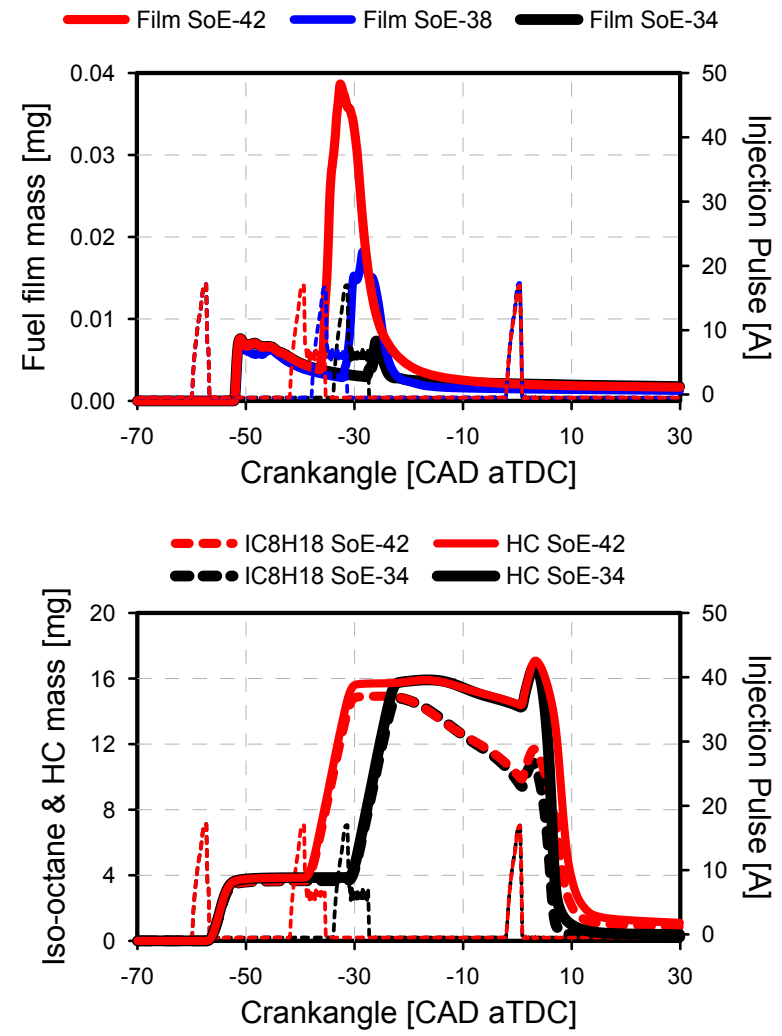

Figure 11: Fuel film mass as function of crankangle for SoE2 42, 38 and 34 CAD aTDC (top plot) and HC with iso-octane mass for SoE2 42 and 34 CAD aTDC (bottom plot). 

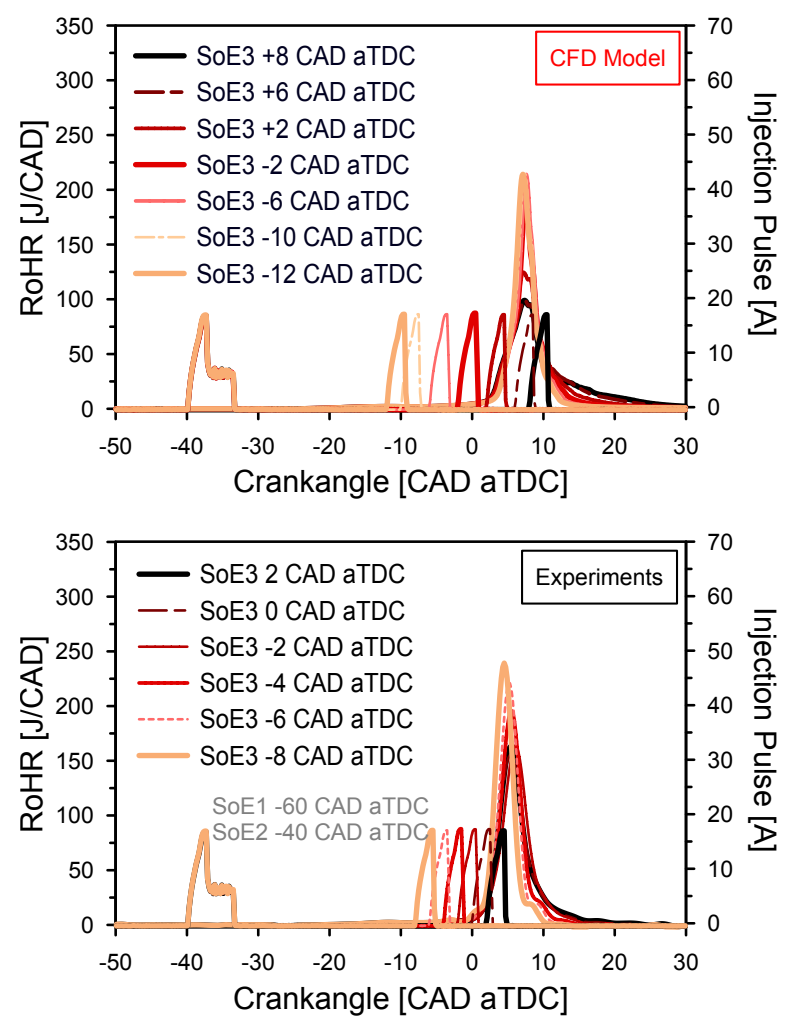

Figure 12: Effect of SoE3. RoHR and injection pulse and for CFD (top plot) and experimental results (bottom plot). 

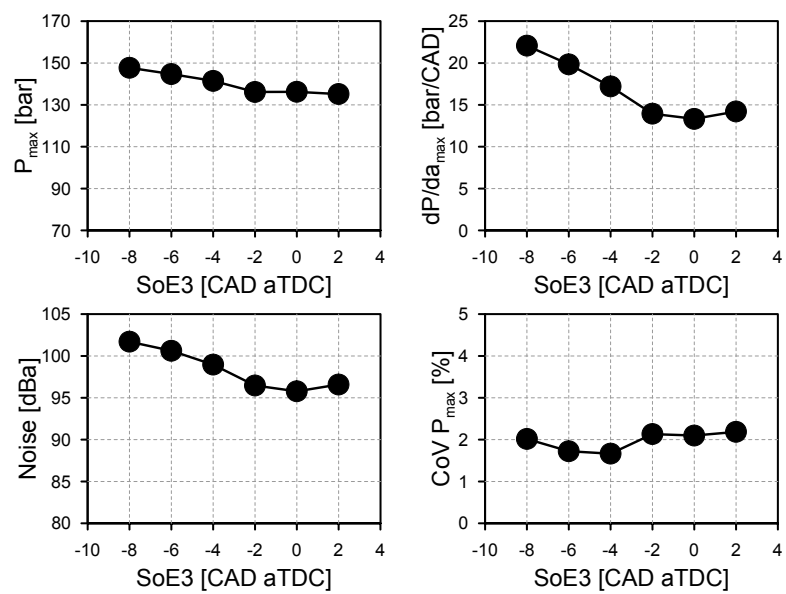

Figure 13: Effect of SoE3. Global combustion parameters for experimental results. 

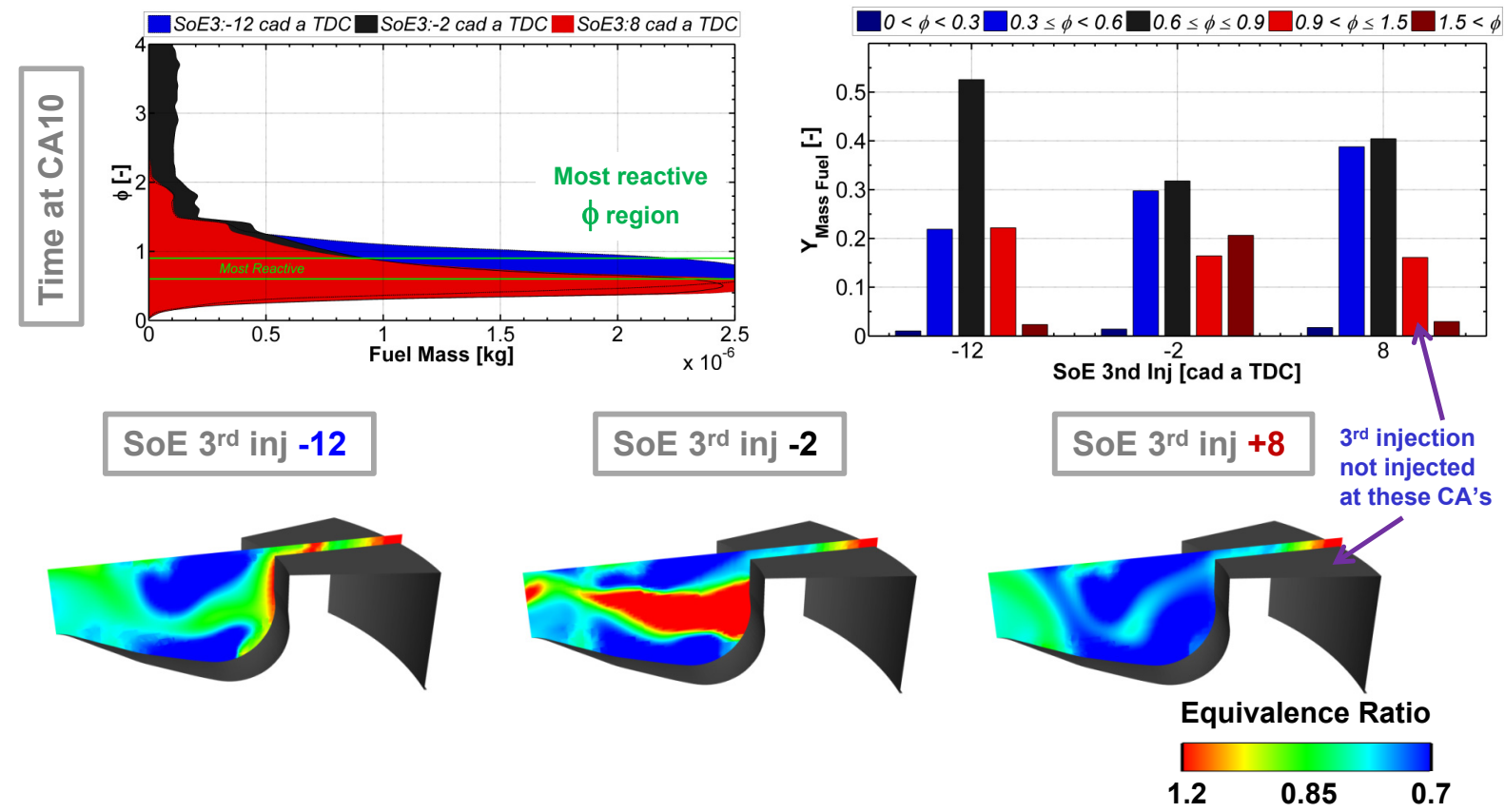

Figure 14: Local conditions evaluated at CA10. Equivalence ratio distribution as function of fuel mass (top-left plot), histogram of fuel mass (top-right plot) and spatial equivalence ratio distribution (bottom plot) for SoE3 equal to -12, -2 (baseline) and +8 CAD aTDC. 

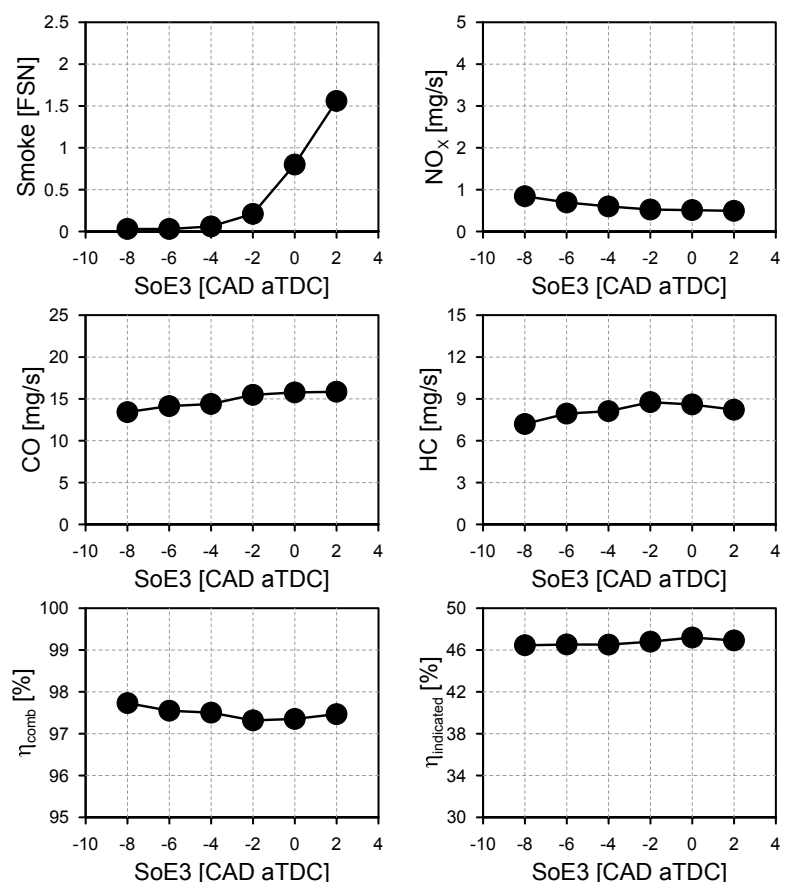

Figure 15: Effect of SoE3. Exhaust emissions and efficiencies for experimental results. 

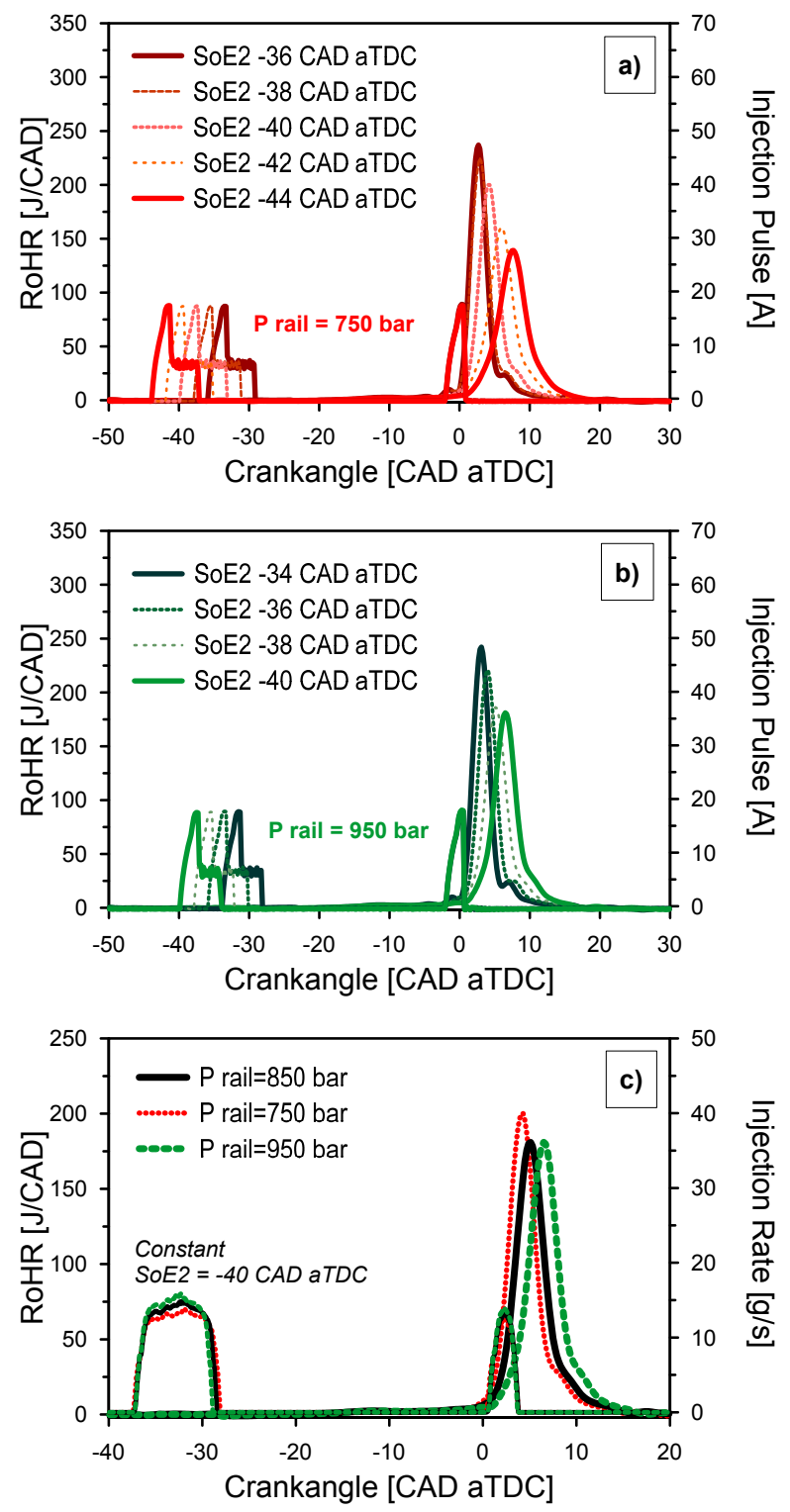

Figure 16: RoHR and injection pulse for SoE2 sweep at $\mathrm{P}_{\text {rail }} 750$ (top plot) and 950 bar (center plot). Comparison between injection rate and RoHR profiles (bottom plot). 

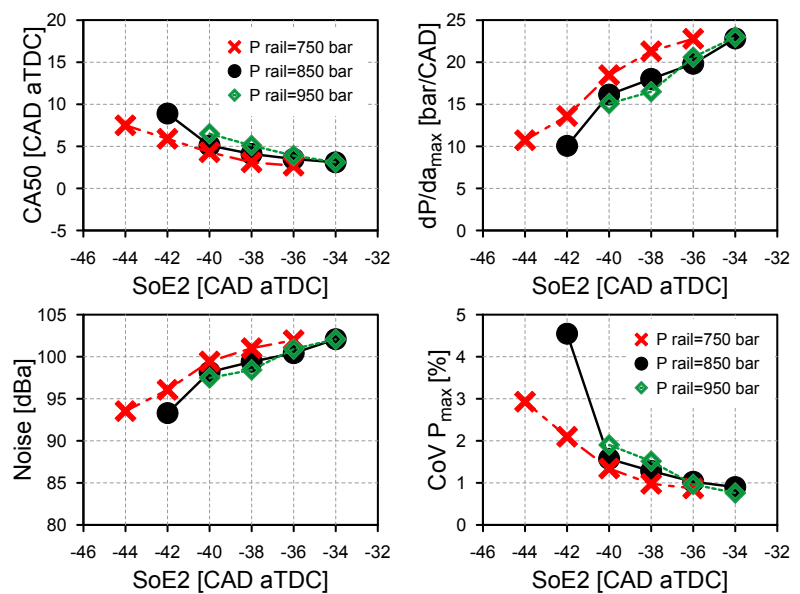

Figure 17: Effect of injection pressure. Global combustion parameters for experimental results. 

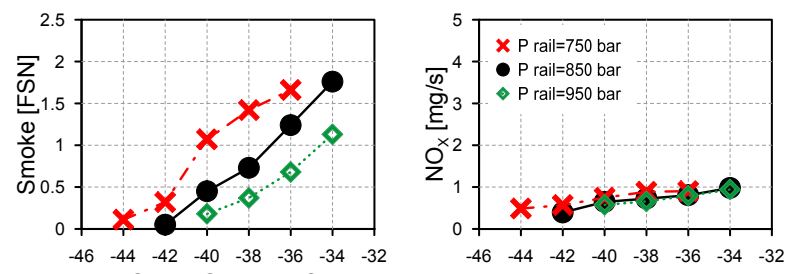

SoE2 [CAD aTDC]

SoE2 [CAD aTDC]
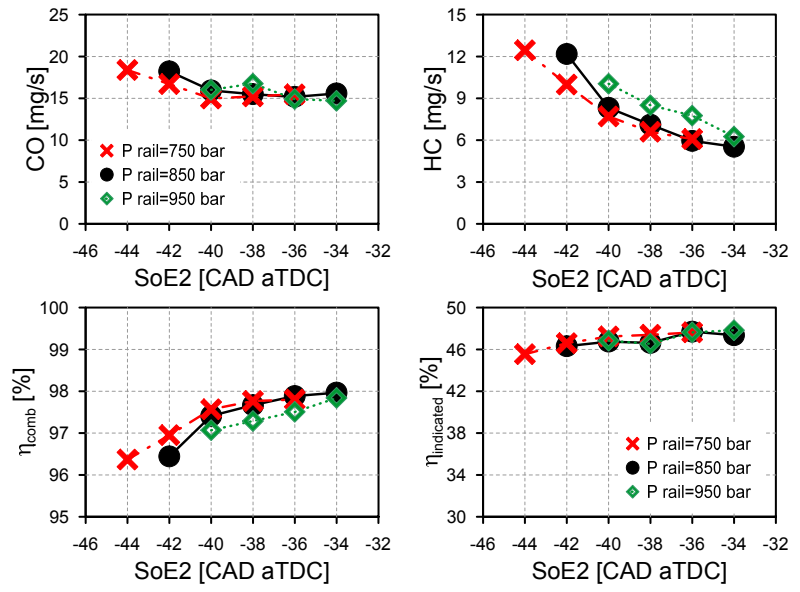

Figure 18: Effect of injection pressure. Exhaust emissions and efficiencies for experimental results. 
List of Tables

$672 \quad 1$ Single cylinder research engine specifications . . . . . . . . . . . . . . . . . . . 45

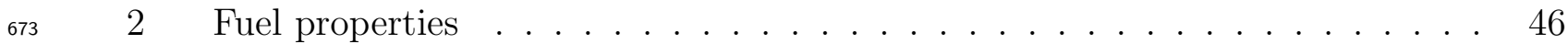

${ }_{674} 3$ Accuracy of the instrumentation used in the research work . . . . . . . . 47

6754 Experimental test conditions, emissions and fuel consumption reference levels from CDC operation. . . . . . . . . . . . . . . . . . . . . . 48 
Table 1: Single cylinder research engine specifications

\begin{tabular}{ll}
\hline Engine type & Single cylinder 2-stroke CI \\
Displacement & $365 \mathrm{~cm}^{3}$ \\
Bore x Stroke & $76 \mathrm{~mm} \times 80.5 \mathrm{~mm}$ \\
Connecting Rod Length & $133.75 \mathrm{~mm}$ \\
Nominal CR & $17.6: 1$ \\
Number of Valves & 4 \\
Type of scavenge & Poppet valves with \\
& scavenge loop \\
Valvetrain & DOHC with VVA \\
Nominal intake valve timing & IVO=161.9 CAD aTDC \\
& IVC=251.6 CAD aTDC \\
Nominal exhaust valve timing & EVO=122.6 CAD aTDC \\
& IVC=226.9 CAD aTDC \\
Fuel injection system & Common rail \\
& Maximum IP=1800 bar \\
& for diesel \\
Injector nozzle & 8 holes x $\varnothing_{\text {hole }} 0.09 \mathrm{~mm}$ \\
& $148^{\circ}$ included angle \\
&
\end{tabular}


Table 2: Fuel properties

\begin{tabular}{ll}
\hline Test fuel & $\begin{array}{l}\text { Calibrated unleaded gasoline } \\
\text { with lubricity additive }\end{array}$ \\
Research Octane Number & 94.6 \\
Motored Octane Number & 84.8 \\
$\mathrm{H} / \mathrm{C}$ ratio & 1.761 \\
$\mathrm{O} / \mathrm{C}$ ratio & 0 \\
$(\mathrm{~A} / \mathrm{F})_{\text {st }}$ (by mass) & 14.37 \\
Lower Heating Value & $42.82 \mathrm{MJ} / \mathrm{kg}$ \\
Density $\left(15^{\circ} \mathrm{C}\right)$ & $758.1 \mathrm{~kg} / \mathrm{m}^{3}$ \\
Kinematic viscosity $\left(40^{\circ} \mathrm{C}\right)$ & $0.44 \mathrm{cSt}$ \\
\hline
\end{tabular}


Table 3: Accuracy of the instrumentation used in the research work

\begin{tabular}{lll}
\hline Sensor & Variable & Accuracy (\%) \\
\hline Piezoelectric & In-cylinder pressure & \pm 0.7 \\
Thermocouples & Temperature of all fluids & \pm 0.35 \\
Encoder & Engine speed & \pm 0.006 \\
Exhaust gas analyzer & Exhaust emissions & \pm 2 \\
& $\left.\mathrm{NO}_{\mathbf{x}}, \mathrm{CO}, \mathrm{HC}, \mathrm{O}_{2}\right)$ & \\
Smoke meter & FSN & \pm 2 \\
Piezoresistive & Intake and exhaust pressure, & \pm 0.65 \\
& in-cylinder pressure at BDC & \\
Torque meter & Torque & \pm 0.1 \\
Fuel mass flow meter & Fuel mass & \pm 0.2 \\
Air mass flow meter & Air mass & \pm 0.12 \\
\hline
\end{tabular}


Table 4: Experimental test conditions, emissions and fuel consumption reference levels from CDC operation.

\begin{tabular}{ll}
\hline Engine speed & $1500 \mathrm{rpm}$ \\
IMEP & $10.4 \mathrm{bar}$ (baseline) \\
Injected fuel quantity & $18.8 \mathrm{mg} /$ stroke \\
Intake air temperature & $35^{\circ} \mathrm{C}$ \\
Coolant and oil temperature & $90^{\circ} \mathrm{C}$ \\
\hline $\mathrm{NO}_{\mathrm{x}}$ reference (CDC) & $2.13 \mathrm{mg} / \mathrm{s}$ \\
Smoke reference (CDC) & $2.99 \mathrm{FSN}$ \\
HC reference (CDC) & $0.36 \mathrm{mg} / \mathrm{s}$ \\
CO reference (CDC) & $13.02 \mathrm{mg} / \mathrm{s}$ \\
Noise reference (CDC) & $86.4 \mathrm{~dB}$ \\
Indicated efficiency (CDC) & $43.4 \%$ \\
ISFC (CDC) $_{\text {ISFC }_{\text {corr }}(\mathrm{CDC})}$ & $196.6 \mathrm{~g} / \mathrm{kWh}$ \\
\hline
\end{tabular}


Table 5: Engine settings for experiments at $1500 \mathrm{rpm} 10.4 \mathrm{bar}$ IMEP.

\begin{tabular}{lccccccccr}
\hline Test & $\begin{array}{c}\text { EGR } \\
(\%)\end{array}$ & $\begin{array}{c}\mathrm{P}_{\text {int }} \\
(\mathrm{bar})\end{array}$ & $\begin{array}{c}\Delta \mathrm{P} \\
(\mathrm{bar})\end{array}$ & $\begin{array}{c}\text { Overlap } \\
(\mathrm{CAD})\end{array}$ & $\begin{array}{c}\mathrm{VVT}_{\text {int,exh }} \\
(\mathrm{CAD})\end{array}$ & $\begin{array}{c}\mathrm{P}_{\text {rail }} \\
(\text { bar })\end{array}$ & $\begin{array}{c}\text { SoE1 } \\
(\mathrm{CAD})\end{array}$ & $\begin{array}{c}\text { SoE2 } \\
(\mathrm{CAD})\end{array}$ & $\begin{array}{c}\text { SoE3 } \\
(\mathrm{CAD})\end{array}$ \\
\hline 4.1 & 43.5 & 2.75 & 0.71 & 78.4 & $(5,20)$ & 850 & {$[\mathbf{- 6 6}$ to $\mathbf{- 5 4}]$} & -40 & -2 \\
\hline 4.2 .1 & 43.5 & 2.75 & 0.71 & 78.4 & $(5,20)$ & 850 & -60 & {$[\mathbf{- 4 2}$ to $\mathbf{- 3 4}]$} & -2 \\
4.2 .2 & 43.5 & 2.75 & 0.71 & 78.4 & $(5,20)$ & 850 & -60 & {$[-\mathbf{4 4}$ to $\mathbf{- 3 6}]$} & -4 \\
4.2 .3 & 43.5 & 2.75 & 0.71 & 78.4 & $(5,20)$ & 850 & -60 & {$[-44$ to $\mathbf{- 4 0}]$} & -6 \\
\hline 4.3 & 43.5 & 2.75 & 0.71 & 78.4 & $(5,20)$ & 850 & -60 & -40 & {$[\mathbf{- 8}$ to 2] } \\
\hline 4.4 .1 & 43.5 & 2.75 & 0.71 & 78.4 & $(5,20)$ & $\mathbf{7 5 0}$ & -60 & {$[-44$ to -36$]$} & -2 \\
4.4 .2 & 43.5 & 2.75 & 0.71 & 78.4 & $(5,20)$ & $\mathbf{9 5 0}$ & -60 & {$[-40$ to -34$]$} & -2 \\
\hline
\end{tabular}

